\title{
Role of the 4-Phosphopantetheinyl Transferase of Trichoderma virens in Secondary Metabolism and Induction of Plant Defense Responses
}

\author{
R. Velázquez-Robledo, ${ }^{1}$ H. A. Contreras-Cornejo, ${ }^{2}$ L. Macías-Rodríguez, ${ }^{2}$ A. Hernández-Morales, ${ }^{1}$ \\ J. Aguirre, ${ }^{3}$ S. Casas-Flores, ${ }^{4}$ J. López-Bucio, ${ }^{2}$ and A. Herrera-Estrella ${ }^{1}$ \\ ${ }^{1}$ Laboratorio Nacional de Genómica para la Biodiversidad and Departamento de Ingeniería Genética de Plantas, CINVESTAV \\ Irapuato, CP 36821, Irapuato, Gto., México; ${ }^{2}$ Universidad Michoacana de San Nicolás de Hidalgo, Instituto de Investigaciones \\ Químico-Biológicas, Ciudad Universitaria, CP 58036 Morelia; Michoacán, México; ${ }^{3}$ Universidad Nacional Autónoma de \\ México, Instituto de Fisiología Celular, Departamento de Biología Celular y Desarrollo, Circuito Exterior S/N Ciudad \\ Universitaria, Coyoacán, 04510, México, D.F.; ${ }^{4}$ División de Biología Molecular, Instituto Potosino de Investigación Científica \\ y Tecnológica, Camino a la Presa San José 2055, Col. Lomas 4 sección CP 78216, San Luis Potosí S.L.P., México
}

Submitted 23 February 2011. Accepted 27 July 2011.

Trichoderma virens is a ubiquitous soil fungus successfully used in biological control due to its efficient colonization of plant roots. In fungi, 4-phosphopantetheinyl transferases (PPTases) activate enzymes involved in primary and secondary metabolism. Therefore, we cloned the PPTase gene ppt1 from $T$. virens and generated PPTase-deficient (Appt1) and overexpressing strains to investigate the role of this enzyme in biocontrol and induction of plant defense responses. The $\Delta p p t 1$ mutants were auxotrophic for lysine, produced nonpigmented conidia, and were unable to synthesize nonribosomal peptides. Although spore germination was severely compromised under both low and high iron availability, mycelial growth occurred faster than the wild type, and the mutants were able to efficiently colonize plant roots. The $\Delta p p t 1$ mutants were unable of inhibiting growth of phytopathogenic fungi in vitro. Arabidopsis thaliana seedlings co-cultivated with wild-type $T$. virens showed increased expression of pPr1a:uidA and pLox2:uidA markers, which correlated with enhanced accumulation of salicylic acid (SA), jasmonic acid, camalexin, and resistance to Botrytis cinerea. Co-cultivation of $A$. thaliana seedlings with $\Delta p p t 1$ mutants compromised the $\mathrm{SA}$ and camalexin responses, resulting in decreased protection against the pathogen. Our data reveal an important role of $T$. virens PPT1 in antibiosis and induction of $\mathrm{SA}$ and camalexin-dependent plant defense responses.

Phosphopantetheinyl transferases (PPTases) belong to a superfamily of enzymes found in prokaryotes and eukaryotes which are required for the synthesis of a wide range of compounds, including fatty acids, amino acids, polyketides, and nonribosomal peptides. PPTases activate carrier proteins in specific biosynthetic pathways by the transfer of a phosphopantetheinyl moiety to an invariant serine residue. PPTases catalyze the nucleophilic attack of the hydroxyl side chain of the conserved carrier protein serine residue on the $5^{\prime}$ - $\beta$-pyro-

Corresponding author: A. Herrera-Estrella: Telephone: +1 52462 1663000; Fax +1 52462 6245849; E-mail: aherrera@ langebio.cinvestav.mx

* The $\boldsymbol{e}$-Xtra logo stands for "electronic extra" and indicates that five supplementary figures are published online and that Figure 1 appears in color online. phosphate linkage of CoA. This causes the transfer of the phosphopantetheinyl moiety of CoA to the side chain of a conserved serine, converting the carrier protein from an inactive apo-form to an active holo-form (Lambalot et al. 1996; Walsh et al. 1997).

The PPT superfamily has been divided into two paralogous groups that correspond to substrate specificity. The first is the AcpS family that comprises homotrimers of 120 to 140 amino acids that are involved in fatty acid biosynthesis in bacteria and fungi (Allen et al. 2011; Hiltunen et al. 2010). Members of the second family such as Sfp are monomeric enzymes of 220 to 240 amino acids, which participate in the synthesis of secondary metabolites by activating nonribosomal peptide synthases (NRPS) and polyketide synthases (PKS) in both bacteria and eukaryotes (Lambalot et al. 1996). This family includes PPTases involved in cyanobacterial heterocyst differentiation, fungal lysine biosynthesis, $\beta$-alanine conjugation, hybrid peptide synthase/polyketide synthase complexes, and other enzymes with an as-yet-unidentified function (Copp and Neilan 2006). A third group of PPTases is characterized by being an integral part of fatty acid synthases in eukaryotes (Mootz et al. 2001).

The importance of PPTases in the synthesis of antibiotics and siderophores has been widely demonstrated in prokaryotes such as Escherichia coli and Pseudomonas syringae (Flugel et al. 2000; Lambalot et al. 1996; Seidle et al. 2006). Many microorganisms possess multiple PPTases. The genome of Bacillus subtilis encodes Sfp for surfactin biosynthesis, and AcpS, involved in siderophore synthesis (Mootz et al. 2001; Ollinger et al. 2006). In comparison, the genome of $E$. coli encodes three PPTases: AcpS and EntD, for synthesis of fatty acids and the siderophore enterobactin; and YhhU, an uncharacterized PPTase (Flugel et al. 2000, Lambalot et al. 1996). These enzymes act in distinct pathways and display contrasting specificity for carrier proteins. The Sfp-like EntD is unable to complement an AcpS mutant of E. coli. In contrast, the B. subtilis Sfp displays a remarkable range of carrier protein substrates (Gehring et al. 1998; Keating and Walsh 1999; Marahiel et al. 1997). When an AcpS-like PPTase is not present in an organism, the Sfp-like PPT will act in both primary and secondary metabolic pathways, displaying a preference for the carrier proteins of fatty acid synthesis (FAS) (Finking et al. 2002). In the case of the fungal antagonistic bacteria $B$. subtilis, a PPTase 
was found to be involved in the synthesis of antibiotics such as surfactin, which promotes induced systemic resistance (ISR) in common bean and tomato (Ongena et al. 2007). Currently, PPTases of the Sfp family have been studied in bacteria pathogenic to humans or plants, or in model systems. In the case of microorganisms used in biological control in agriculture, one of the few cases in which their function has been studied is that of P. luminescens (Chiche et al. 2001). This bacterium is associated with an entomopathogenic nematode, and its corresponding PPTase was found to be essential for the synthesis of toxins that kill the insect.

In fungi, there is still limited information about the role of PPTases. A single multifunctional PPTase has been described in Aspergillus nidulans (Keszenman-Pereyra et al. 2003; Márquez-Fernández et al. 2007; Oberegger et al. 2003). Similar findings were reported in A. fumigatus (Neville et al. 2005), Penicillium chyrisogenum (García-Estrada et al. 2008), and the plant pathogens Colletotrichum graminicola and Magnaporthe oryzea (Horbach et al. 2009). However, recently, a mitochondrial PPTasa (PptB) of the AcpS type, specific for the mitochondrial acyl carrier protein AcpA, was reported in A. fumigatus (Allen et al. 2011). These studies also demonstrated that PPTases are necessary for synthesis of lysine and many secondary metabolites, including antibiotics, siderophores, and pigments.

The genus Trichoderma comprises a large number of filamentous fungi of wide distribution in agricultural ecosystems, which are well characterized in terms of production of polyketides and nonribosomal peptides (Reino et al. 2007). A single NRPS can produce up to three distinct peptaibols. Accordingly, Neuhof and co-workers (2007) analyzed 34 phylogenetically related Trichoderma strains, identifying 58 different classes of peptaibols. Several species of the genus Trichoderma are necrotrophic mycoparasites of phytopathogenic fungi and are widely used in biological control of diseases in agriculturally important crops. Moreover, some Trichoderma isolates are capable of activating plant defense responses (Yedidia et al. 1999, 2003).

Plants possess various inducible defense mechanisms for protection against pathogen attack. An example of this is systemic acquired resistance (SAR), which is activated after infection by necrotizing pathogens (Ryals et al. 1996). Similarly, colonization of plant roots by certain nonpathogenic rhizobacteria can produce ISR in the host plant (van Loon et al. 1998). ISR is a plant-mediated mechanism similar to SAR which is initiated at the root and extends up to the shoot, conferring protection against different types of plant pathogens. Induction of ISR depends, in part, on phytohormone signaling mediated by jasmonic acid (JA) and ethylene (ET) (Glazebrook 2005). Accumulation of antimicrobial metabolites is integral to plant protection. In Arabidopsis thaliana, accumulation of the phytoalexin camalexin was found in tissue exposed to infection by either avirulent or virulent strains of the bacterium Pseudomonas syringae (Glazebrook and Ausubel 1994; Tsuji et al. 1992) and after inoculation with the fungus Cochliobolus carbonum (Glazebrook et al. 1997). In vitro studies demonstrated that camalexin inhibits bacterial and fungal growth (Ferrari et al. 2003; Jejelowo et al. 1991; Rogers et al. 1996; Tsuji et al. 1992).

There is a wide range of hormone-like factors that affect the responses of plants to Trichoderma spp. In cucumber ( $\mathrm{Cucu-}$ mis sativus) and maize (Zea mays), the main signaling pathway by which Trichoderma virens induces systemic resistance involves JA and ET (Djonovi et al. 2007; Yedidia et al. 2003). Both salicylic acid (SA) and JA changes have been previously described in cucumber plants inoculated with T. asperellum T34 (Segarra et al. 2007), indicating that hormonal defense protection of plants is widespread among Trichoderma spp. By using an Arabidopsis-Trichoderma co-cultivation system, we analyzed the response of pathogenesis-related reporter genes to $T$. virens or $T$. atroviride, which provided evidence that the defense signaling pathway activated by these fungi involves SA and JA (Salas-Marina et al. 2011). Interestingly, accumulating evidence suggests that the 18-mer peptaibols are critical for the chemical communication between Trichoderma spp. and the plant (Brotman et al. 2009; Viterbo et al. 2007). In fact, the peptaibol alameticin produced by $T$. viride sprayed on Phaseolus lunatus plants activates ISR, resulting in the production of defense compounds against herbivores (Engelberth et al. 2000). In a more recent study, cucumber plants co-cultivated with $T$. virens strains disrupted in the NRPS encoding gene tex 1 showed a significant reduction in systemic resistance against the leaf pathogen Pseudomonas syringae pv. lachrymans, and reduced production of phenolic compounds with inhibitory activity against this bacterium (Viterbo et al. 2007).

Here, we report the characterization of $T$. virens mutants defective in the pptl gene and show that the corresponding protein is required for the synthesis of lysine, peptaibols, pigments, and siderophores. The $\Delta p p t 1$ mutants showed a dramatically reduced capacity to inhibit the growth of phytopathogenic fungi in vitro. In addition, decreased activation of ISR in A. thaliana was observed when plants were grown in association with $T$. virens lacking PPTase PPT1, which correlated with a reduction in SA and camalexin levels in plants. Surprisingly, the production of JA and activation of JA-dependent pLox2:uidA were still observed in plants co-cultivated with $T$. virens $\Delta p p t 1$ mutants, even though the mutants failed to produce polyketides and nonribosomal peptides. Our results reveal a key role of $T$. virens PPTase in antibiosis, and the specific induction of SA and camalexindependent plant defense responses.

\section{RESULTS}

\section{T. virens ppt 1 mutants produce nonpigmented conidia, show enhanced growth, and require supplemental iron to germinate.}

Bioinformatics analysis of the sequenced genomes of members of the genus Trichoderma revealed that there are three sequences with similarity to PPTases in the genome of $T$. virens (protein ID 194983 of the Sfp type, protein ID 203026 of the AcpS type, and protein ID 48659 of the fatty acid synthesis type I), as well as those of T. atroviride (protein ID 52102 of the Sfp type, protein ID 286047 of the AcpS type, and protein ID 85662 of the fatty acid synthesis type I), whereas that of $T$. reesei has only two PPTases (protein ID 56081 of the AcpS type and protein ID 48788 of the fatty acid synthesis type I). Analysis of the deduced protein sequence of the $T$. virens gene (ppt1), corresponding to the PPTase of the Sfp type (ID 194983) indicated that it contains the conserved motifs FNVTHQ (102 to 107$)$, VAIGTD (123 to 128 ), and WCLREAYVK (188 to 196) characteristic of PPTases. To determine the functional role of the $T$. virens phosphopantetheinyl transferase, the ppt 1 gene was replaced by the $T$. virens arg 2 gene in the arginine auxotrophic strain Tv10.4 of T. virens (Supplementary Fig. 1). Gene replacement was confirmed by polymerase chain reaction (PCR) and Southern blot. A null mutant was then retransformed with the wild-type pptl gene to verify that all observed phenotypes were due to the replacement of the gene. Mutant complementation was confirmed by Southern blot, showing the integration of multiple copies of the gene in the complemented strains (data not shown), and the complemented strain included in all subsequent analyses. To determine if PPT1 is a limiting factor for the activation of PKS and NRPS in $T$. virens, overexpressing strains were generated by transformation of the wild-type strain using a plasmid containing the cod- 
ing sequence of pptl fused to the constitutive promoter of the T. reese $i$ pyruvate kinase gene. Integration of the construct was confirmed in two transformants by Southern blot (Supplementary Fig. 2). Analysis of the expression of pptl in these transformants (OEppt1-4 and OEppt1-6) revealed high levels of expression, whereas no mRNA could be detected in the wildtype strain (Supplementary Fig. 3). Expression of the gene in the wild-type strain (Tv29.8), the parental strain used to generate the mutant (Tv10.4), and the retransformed strain (TvC-24) used throughout our studies was confirmed by reverse-transcription PCR (data not shown).

The evaluation of growth and conidiation of the mutant ( $\Delta p p t 1-1)$ and complemented (TvC-24) strains in comparison with the wild-type (Tv29.8) and parental (Tv10.4) strains was carried out (Fig. 1A and B). A fluffy phenotype was observed in the gene-replacement mutant, which unexpectedly had a marked increase in radial growth (93\%) compared with the wild type (Fig. 1A and $\mathrm{C}$ ). In addition, the mutant produced white conidia, lacking the characteristic green pigment of the wild type (Fig. 1A), suggesting that the mutation likely affected the activation of the polyketide synthase responsible for the synthesis of this pigment. As expected, these phenotypes disappeared in the complemented strains, which showed no difference in growth or conidiation when compared with the wild-type strain (Fig. 1B and C). All $\Delta p p t 1$ mutants obtained behaved similarly (data not shown).

Growth of the wild-type and mutant strains in minimal medium supplemented with iron revealed a clear reduction in conidial germination, which was even more drastically reduced in the absence of iron, suggesting an important role of siderophores in the iron capture mechanism necessary for germination of conidia (Fig. 2A and B). To determine whether the mutation also affected iron capture during active growth, the mutant was evaluated in minimal medium with or without iron and without the addition of siderophores. In contrast to germination of conidia, the mutant grew without any apparent problem without iron, although the mycelium was scarce and growth was arrested after $72 \mathrm{~h}$ (Fig. 2C). In medium supplemented with iron, the mutant grew normally and produced abundant mycelium (Fig. 2D).

\section{The ppt1 mutants show decreased antagonistic activity against phytopathogens.}

To better understand the role played by secondary metabolites in the control of phytopathogenic fungi by $T$. virens, we evaluated the inhibitory activity of small molecules produced by the different Trichoderma strains generated on the growth of seven phytopathogenic fungi (Alternaria solani, Fusarium spp., Fusarium oxysporum, Phytophthora capsici, Rhizoctonia solani, Sclerotium rolfsii, and S. cepivorum). The growth of all pathogens was completely inhibited when grown in media where the wild type, overexpressing, or complemented Trichoderma strains had been pregrown, with the exception of $S$. rolfsii, which only showed a delay in growth. In contrast, the growth of pathogens in medium where the $\Delta p p t 1$ strain had been pregrown was unaffected, except in the cases of Fusarium spp. and $F$. oxysporum, which grew but whose colonies clearly showed less dense mycelial mats (Fig. 3A). All seven phytopathogens grew normally in the medium without Trichoderma metabolites. These data suggested that the lack of activation of PKS and NRPS, responsible for the production of most secondary metabolites by Trichoderma spp., severely affects the capacity of $T$. virens to inhibit the growth of phytopathogenic fungi. To confirm that the loss of this capacity was due to the lack of antibiotic production, mycelial extracts of Trichoderma spp. grown in liquid medium were analyzed by mass spectrometry using electrospray ionization quantitative time-of-flight (ESI-QTOF). In the cases of parental Tv10.4 (Fig. 3B) and wild-type Tv29.8 strains (data not shown), three classes of peptaibols were identified by mass spectrometry analysis, including those previously reported: 11,14 , and 18 mer (Viterbo et al. 2007). In contrast, the $\Delta p p t 1$ mutant did not produce any of these metabolites (Fig. 3C), confirming that mutation of the corresponding gene severely affects the synthesis of peptaibols, thus decreasing the potential of Trichoderma spp. to inhibit the growth of other fungi.

\section{T. virens $\Delta p p t 1$ mutants are capable of colonizing plant roots.}

It has previously been demonstrated that Trichoderma spp. colonize plant roots. Following root penetration, the exchange of bioactive compounds controls the endophytic proliferation of the fungus (Chacón et al. 2007; Yedidia et al. 1999). Although it has been shown that some secondary metabolites may potentiate systemic induced response, it is not known if they play a role in the plant-Trichoderma communication. For this reason, the colonization of Solanum lycopersicum roots by wild-type $T$. virens and $\Delta p p t 1$ mutants in vitro and their permanence in the root system were analyzed. Using vital staining of fungal hyphae and confocal microscopy, we detected the presence of all tested strains of T. virens Tv10.4, Tv29.8, and $\Delta$ ppt1-1 in the root epidermis after $48 \mathrm{~h}$ of plant-fungus interaction. At this time, all strains were present in the first cell layers of the root (Fig. 4B to D). Twenty-four hours later, the strains Tv10.4, Tv29.8, and TvC-24 colonized the root system without extending to the aerial part of the plant, whereas the $\Delta p p t 1$ mutant colonized the root system but also invaded the stem of the plant (Supplementary Fig. 4). After $72 \mathrm{~h}$ of the interaction, plants were transferred to soil and grown for 15 additional days. At the end of this period, persistence of

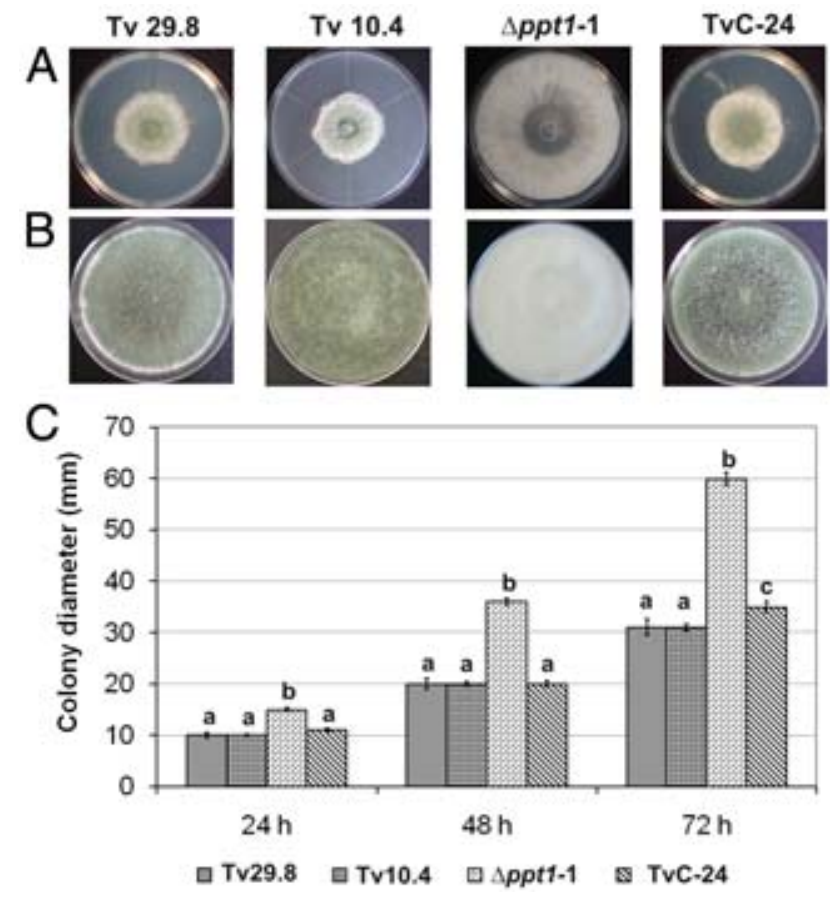

Fig. 1. Trichoderma virens mutants in pptl are altered in growth and conidiation. Representative photographs showing the aspect of the colonies of the strains photographed after $\mathbf{A}, 72$ or $\mathbf{B}, 120 \mathrm{~h}$ of growth at $28^{\circ} \mathrm{C}$ in potato dextrose agar (PDA). Names on top of columns indicate the $T$. virens strain evaluated. $\mathbf{C}$, Kinetics of growth of the indicated strains in PDA as determined by measuring colony diameter. Values shown represent the mean of three different plates \pm standard deviation. Means with different letter in a column are statistically different $(P \leq 0.05)$. The experiment was repeated twice with similar results. 
Trichoderma spp. in the roots was evaluated by recovering them from surface-sterilized root fragments in selective media (Fig. 4E to $\mathrm{H}$ ). Even though the gene replacement mutant (Appt1-1) and the parental strain (Tv10.4) were auxotrophic for lysine and arginine, respectively, they could survive in the root system. The identity of the recovered strains was confirmed by PCR using oligonucleotides ppt $1-G$ and $p p t 1-H$ that allowed the distinction between the wild type and the gene replacement mutant (data not shown).

\section{Nonribosomal peptides and polyketides play a minor role} in seed protection by Trichoderma spp.

The role of antibiotics in fungal antagonism by Trichoderma spp. has been well established in vitro, and synergism with cell wall-degrading enzymes has also been observed (Schirmböck et al. 1994). In spite of the efforts made to understand the role of antibiotics in the interaction with the plant (Tijerino et al. 2011; Vinale et al. 2006), their role in vivo remains poorly understood. Therefore, we next investigated the role of nonribosomal peptides and polyketides from $T$. virens in seed protection through the analysis of the protection conferred by wildtype $T$. virens and $\Delta p p t 1$ mutants to $S$. lycopersicum seeds exposed to a substrate infested with $R$. solani. By measuring seed germination, we determined that, without Trichoderma spp., only $45 \%$ of $S$. lycopersicum seeds germinated in the presence of $R$. solani. Seed treated with $T$. virens Tv29.8 and Tv10.4 behaved similarly, showing $65 \%$ germination. A contrasting result was obtained when seeds were treated with the genereplacement mutant, which apparently were more efficiently protected, showing $77 \%$ germination (Fig. 5A). Axenic seeds or $T$. virens wild-type and $\Delta p p t 1-1-$ treated seeds showed a
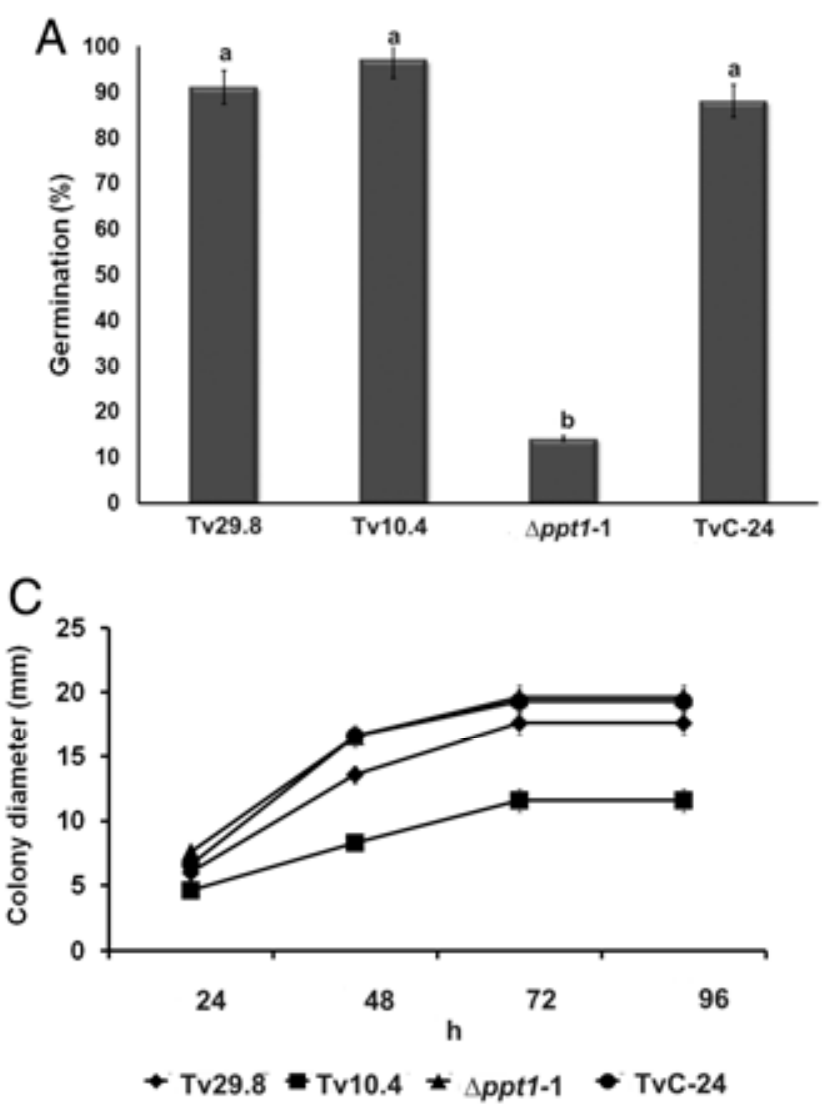

Fig. 2. The Sppt1 mutant of Trichoderma virens is affected in germination of conidia. Germination of conidia of the indicated T. virens strains in VMS medium (Viterbo et al. 2007) A, with or B, without iron. Mycelial growth of the indicated T. virens strains in Grimm-Allen medium C, with or D, without iron. A to D, Bars indicate standard deviation. Means with different letter in a column are statistically different $(P \leq 0.05)$. The experiment was repeated twice with similar results.

1462 / Molecular Plant-Microbe Interactions 
Interaction between $A$. thaliana roots and $T$. virens $\Delta p p t 1$ mutant fail to induce $S A$ accumulation in leaves.

To determine whether the changes in the expression of $\mathrm{pPr}$ 1a:uidA and pLox2:uidA markers were associated with changes in endogenous SA or JA content in plants co-cultivated with Trichoderma spp., free SA and JA were measured in wild-type A. thaliana (Col-0) plants co-cultivated with wild-type $T$. virens or $\Delta p p t 1$ mutants by gas chromatography-mass spectrometry (GC-MS). A fourfold increased accumulation in SA was observed in treatments with wild-type Trichoderma spp. when compared with axenically grown seedlings (Fig. 7A). The levels of SA dramatically decreased in plants co-cultivated with the $\Delta p p t$ 1-1 mutant (Fig. 7A). In contrast, JA determinations clearly showed a three- to fourfold increase in JA in plants that were co-cultivated with either wild-type T. virens or sppt1-1 mutant strains (Fig. 7B).

\section{Trichoderma $\Delta p p t 1$ mutants fail}

to induce camalexin accumulation in A. thaliana.

To investigate whether deletion of ppt1 could affect camalexin production, axenically grown plants, or plants colonized with wild-type $T$. virens or the $\Delta p p t 1-1$ mutant were used for camalexin determinations. GC-MS analysis revealed that $A$. thaliana seedlings interacting with wild-type $T$. virens increased camalexin levels by three- to fourfold when compared with axenically grown plants (Fig. 8). This effect was highly reduced in plants co-cultivated with $\Delta p p t 1$ mutants (Fig. 8).

\section{Deletion of ppt1 compromises $T$. virens protection} against the necrotizing pathogen Botrytis cinerea.

To determine whether the alterations in SA and camalexindependent responses observed in A. thaliana seedlings exposed to $\Delta p p t 1$ mutants could affect pathogen resistance, we tested the responses of leaves from 12-day-old Arabidopsis plants whose roots had been colonized or not with wild-type $T$. virens or $\Delta p p t 1$ mutant and inoculated with the necrotrophic pathogen Botrytis cinerea, which causes spreading necrotic lesions on leaves. In these experiments, $B$. cinerea spores were inoculated on the leaf surface and disease symptoms evaluated 3 and 5 days later. In control plants, $B$. cinerea was found to induce necrotic lesions in approximately $55 \%$ of inoculated leaves (Fig. 9A). In contrast, in plants colonized by the $T$. virens wild type, only $29 \%$ presented necrotic lesions caused by $B$. cinerea infection (Fig. 9A), whereas plants co-cultivated with the $\Delta p p t 1$ mutant showed levels of necrotic lesions similar to the control plants (Fig. 9A). Furthermore, B. cinerea caused death
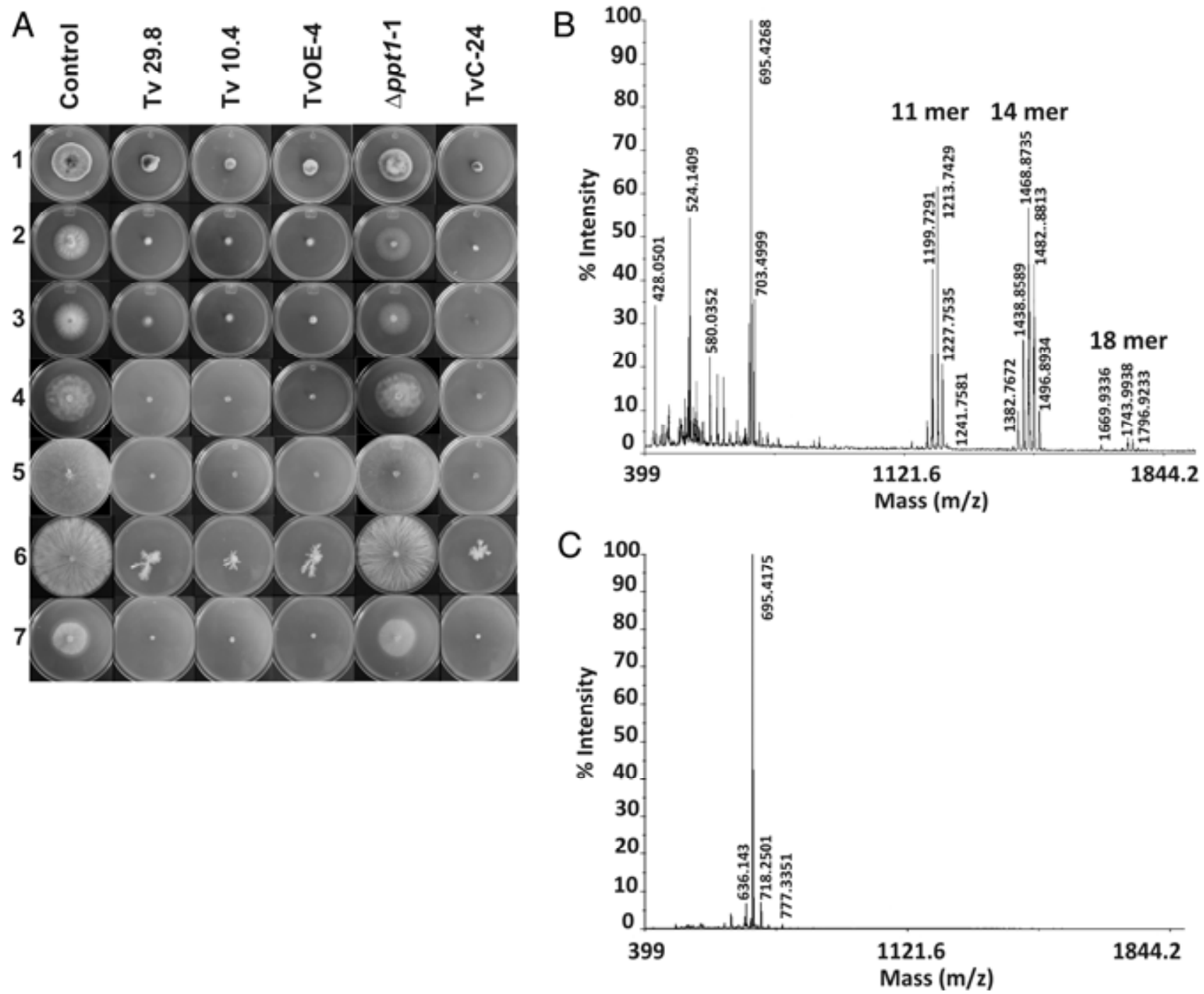

Fig. 3. Effect of antibiotics from Trichoderma virens on phytopathogenic fungi and production of peptaibols. A, Growth of phytopathogens on plates where Trichoderma had been pregrown photographed after $48 \mathrm{~h}$ of growth. Row 1, Alternaria solani; row 2, Fusarium spp.; row 3, Fusarium oxysporum; row 4, Phytophthora capsici; row 5, Rhizoctonia solani; row 6, Sclerotium rolfsii; row 7, S. cepivorum. Names on top of each column indicate the T. virens strain evaluated. Detection of peptaibols by mass spectrometry in extracts from strains $\mathbf{B}, \mathrm{Tv} 10.4$ and $\mathbf{C}, \Delta p p t 1-1$. 
in approximately $90 \%$ of control plants, in contrast to only $25 \%$ death in plants colonized by the wild-type Trichoderma strain, whereas the ppt 1 mutant failed to confer protection (Fig. 9B).

\section{DISCUSSION}

Phosphopantetheinyl transferases compose a class of ubiquitous enzymes found in filamentous fungi, which are necessary for primary metabolism due to their role in activating the $\alpha$ aminoadipato reductase and in secondary metabolism for the activation of polyketide synthases and NRPS. Here, we report the role of an Sfp-class phosphopantetheinyl transferase from T. virens in fungal physiology, biocontrol, and plant interaction.

We observed that $\Delta p p t 1$ mutants of $T$. virens had an accelerated radial growth of vegetative hyphae and delayed production of conidia. Conidia were produced only when growth of aerial hyphae decreased. A similar alteration in vegetative growth and a sharp decrease in conidiation were reported in the cfwA/npgA mutant of Aspergillus nidulans, which was attributed to a delay in hyphal branching (Márquez-Fernández et al. 2007). Increased growth was also observed in the conditional mutant $n p g A / c f w A$ from $A$. nidulans, which produced more mycelial mass than the wild type in liquid culture (Keszenman-Pereyra et al. 2003). We hypothesize that the enhanced mycelium growth and decreased conidiation in the $T$. virens $\Delta p p t 1$ mutant is due to the lack of production of secondary metabolites, because growth of the mutant in media with such metabolites excreted by the wild type were sufficient to revert this phenotype, as well as the fluffy aspect of the colony. A plausible explanation is that the peptaibols produced by Trichoderma spp. can affect its own plasma membrane functions, and that the lack of production of these metabolites by the mutant potentiates growth, leading to the production of more aerial mycelium. Although it has never been reported that $T$. virens's own antibiotics could affect its growth or conidiation, Howell and Stipanovic (1983) reported that a vir- idiol overproducing mutant of $T$. virens (formerly Gliocladium virens) grew more slowly than the parental strain.

When grown in media with low or high iron concentration, conidia of the $\Delta p p t 1$ mutant showed low germination index. In this respect, trihydroxamates such as ferricrocin are essential to store iron intracellularly, which aids spore germination in iron-poor media, as demonstrated for sidC in A. fumigatus (Schrettl et al. 2007), A. nidulans (Wallner et al. 2009), and Neurospora crassa (Berthold et al. 1987; Charlang and Williamst

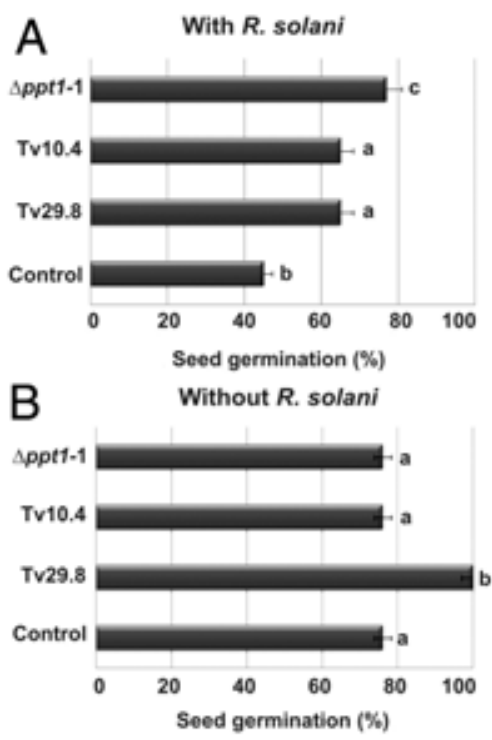

Fig. 5. Protection of Solanum lycopersicum seeds by Trichoderma spp. A, Effect of inoculation of the indicated Trichoderma virens strains on germination of seeds in soil infested with Rhizoctonia solani. B, Effect of inoculation of $T$. virens on germination of seeds in sterile soil. $\mathbf{A}$ and $\mathbf{B}$, Control corresponds to uninoculated seed. Bars indicate standard deviation. Means with different letter in a column are statistically different $(P \leq 0.05)$. The experiment was repeated twice with similar results.
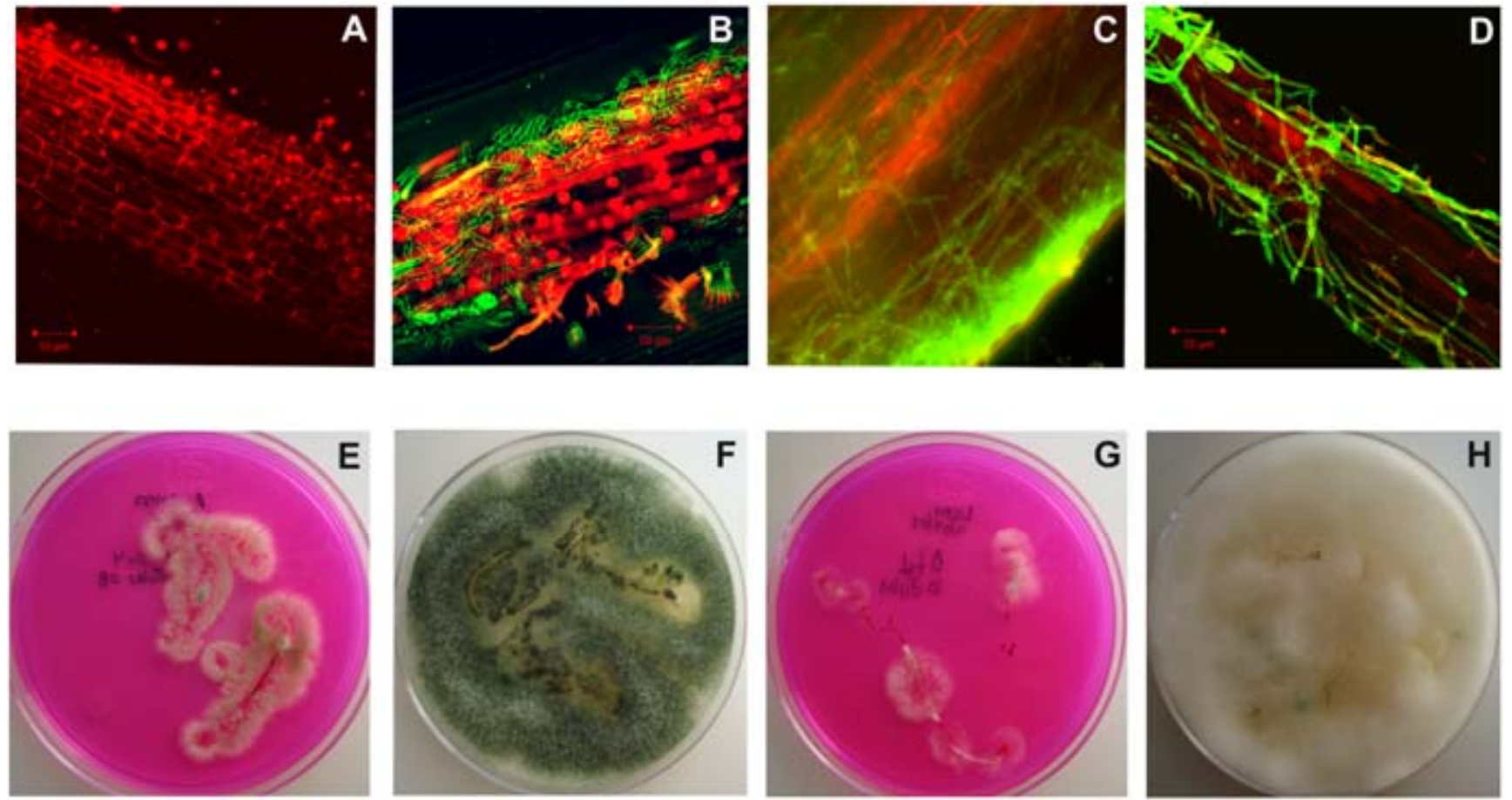

Fig. 4. Colonization of Solanum lycopersicum roots. Top: Confocal microscopy representative photographs of A, roots without Trichoderma spp. or roots colonized by B, Tv 29.8; C, Tv10.4; or D, $\Delta p p t 1-1$ strains. Bottom: Trichoderma strains recovered from root fragments; E, $\Delta p p t 1-1$ and G, Tv10.4 recovered and grown in Rose Bengal selective medium; $\mathbf{F}, \Delta p p t 1-1$ and $\mathbf{H}$, Tv10.4 strains recovered and grown in potato dextrose agar. 
1977). On the other hand, when mycelial growth of the null mutant of $T$. virens was analyzed under iron-limiting conditions, it grew at approximately the same rate as observed for the wild-type strain, although mycelium was scarce. Similar results were also observed in cfwA and PPT1 mutants in A. nidulans and Colletotrichum graminicola, respectively (Horbach et al. 2009; Oberegger et al. 2003). The observed phenotype might be due to the lack of cis/trans fusarinine and dimerum acid, which trap extracellular iron, and might be substituted by the reductive iron assimilation (RIA) pathway, a two-step process that involves the extracellular reduction of $\mathrm{Fe}^{3+}$ to $\mathrm{Fe}^{2+}$ followed by high-affinity uptake of $\mathrm{Fe}_{2}$. In this sense, several orthologous genes to the three components of RIA (Fre1, FetC, and FtrA) were found in the T. virens genome.

One of the main attributes of the genus Trichoderma is the production of secondary metabolites that inhibit the growth of or kill phytopathogenic fungi and some gram-positive bacteria in vitro (Fravel 1988; Neuhof et al. 2007; Reino et al. 2007; Wiest et al. 2002). Among the main antibiotics produced by $T$. virens, peptaibols have deserved more attention. Peptaibols of class 11,14 , and 18 mer were produced by the wild-type strain of $T$. virens as well as the strain used for transformation (Tv10.4), which correspond to those classified as short (11 to 16 amino acids) and long (18 to 20 amino acids) sequences. These peptaibols belong to the TvA class, which is a mix of 11-amino-acid peptides similar to Harzianines $\mathrm{HB}$, and class TvBI Trichorzins type, with 18 residues (Wiest et al. 2002). These peptaibols were reported in the study of the function of the $T$. virens 29.8 NRPS encoding gene texl, where the corresponding mutants failed to produce 18-, 14-, and 11-aminoacid residue peptides peptaibols (Viterbo et al. 2007; Wiest et al. 2002). Our results showed that the $\Delta p p t 1-1$ mutant did not produce peptaibols, thus indicating that the NRPS that participate in their synthesis require PPT1 for their activation.

The role of nonribosomal peptides and polyketides in antagonism by the different $T$. virens strains analyzed here was evaluated through their effects on the growth of several phytopathogenic fungi. Overexpression of ppt1 did not result in increased inhibitory capacity. In contrast, $\Delta p p t 1$ mutants showed strongly decreased antagonistic activity against phytopathogens, suggesting that normal PPT1 function is an important factor in biocontrol by $T$. virens, and that higher levels of PPT1 do not seem to result in increased antagonistic activity by $T$. virens.

An important application of microbial antagonists is seed protection, which allows plant germination in pathogen-infested soils. However, the role of antibiotics produced by Trichoderma spp. in plant protection in soil has remained speculative. The fact that the $\Delta p p t 1-1$ mutant of $T$. virens conferred greater protection to seed of $S$. lycopersicum in soil infested with $R$. solani than the wild-type and parental strains indicates that nonribosomal peptide and polyketide antibiotics play a minor role in seed protection by $T$. virens. The higher protection observed with the $\Delta p p t 1-1$ mutant could be due to the fact that the mutant grows faster, increasing its competition capacity, although we cannot discard the possibility that other antimicrobial compounds are overproduced by Trichoderma spp. in the absence of active NRPS or PKS, which might aid in seed protection. Our findings suggest that hydrolytic enzymes and mycoparasitism are more relevant than antibiotics in the control of $R$. solani during seed protection. A similar observation was made in the case of a $T$. virens mutant that did not produce gliotoxin but remained efficient in the protection of plants against infection by $R$. solani (Howell and Stipanovic 1995).

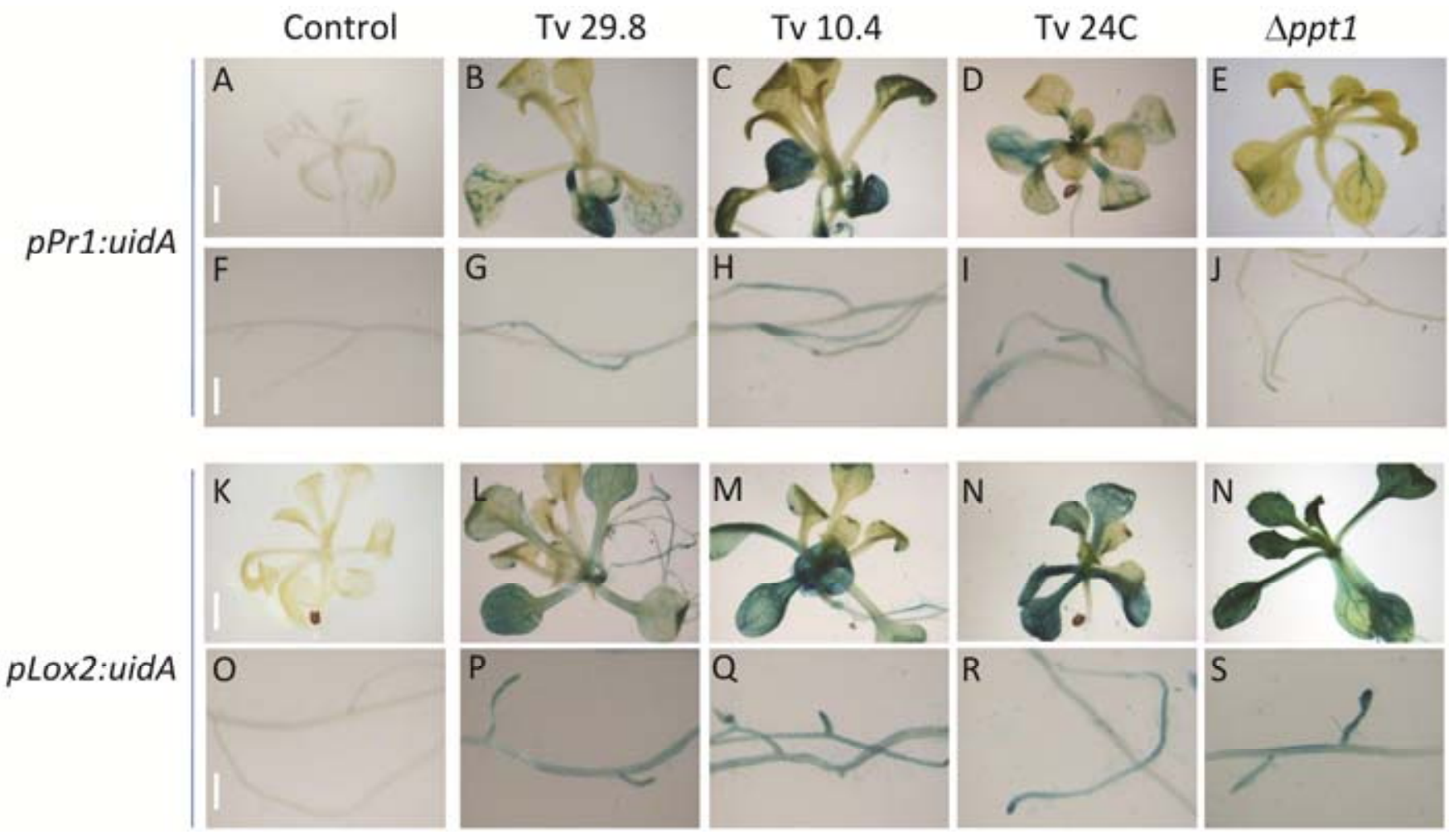

Fig. 6. Effect of Trichoderma virens on expression of the pathogen-related response markers pPrla:uidA and pLox2:uidA. Transgenic Arabidopsis thaliana seedlings carrying the marker constructs were germinated and grown for 4 days on $0.2 \times$ Murashige and Skoog plates, transferred to $0.2 \times$ Murashige and Skoog medium supplemented with $300 \mu \mathrm{M}$ Lys, and then co-cultivated with the T. virens strains indicated on top. $\beta$-Glucuronidase (GUS) expression in seedlings was determined 6 days after transfer. A to $\mathbf{J}$, Plants carrying the pPrla:uidA construct. $\mathbf{K}$ to $\mathbf{S}$, Plants carrying the $p L o x 2:$ uidA construct. A, F, K, and $\mathbf{O}$, Axenically grown plants. A to $\mathbf{E}$ and $\mathbf{K}$ to $\mathbf{N}$, GUS expression in aerial parts of the plant. $\mathbf{F}$ to $\mathbf{J}$ and $\mathbf{O}$ to $\mathbf{S}$, GUS expression in roots. Photographs show representative individuals of at least 20 stained seedlings. The experiment was repeated twice with similar results. 
As in other fungi, $T$. virens $\Delta p p t 1$ mutants are auxotrophic to lysine. This represented an obstacle in evaluating the role of PPT1 in biocontrol. To overcome this obstacle, we analyzed the possibility of allowing colonization of the root system of $S$. lycopersicum plantlets in vitro and then transferring them into soil. The root system was colonized after $48 \mathrm{~h}$ and the fungus remained in plants up to 3 weeks. This is explained by the fact that root exudates of $S$. lycopersicum contain essential amino acids such as lysine, arginine, aspartic acid, and glutamic acid, among others, that provide the requirements for growth (Simons et al. 1997).

Some natural isolates of Trichoderma spp. have been found to colonize not only plant roots but also other parts of the plant, as in the case of Theobroma cacao, colonizing roots, stem, leaves, and even seed (Bailey et al. 2006). By using an in vitro system, we showed that the $\Delta p p t 1-1$ mutant colonized the
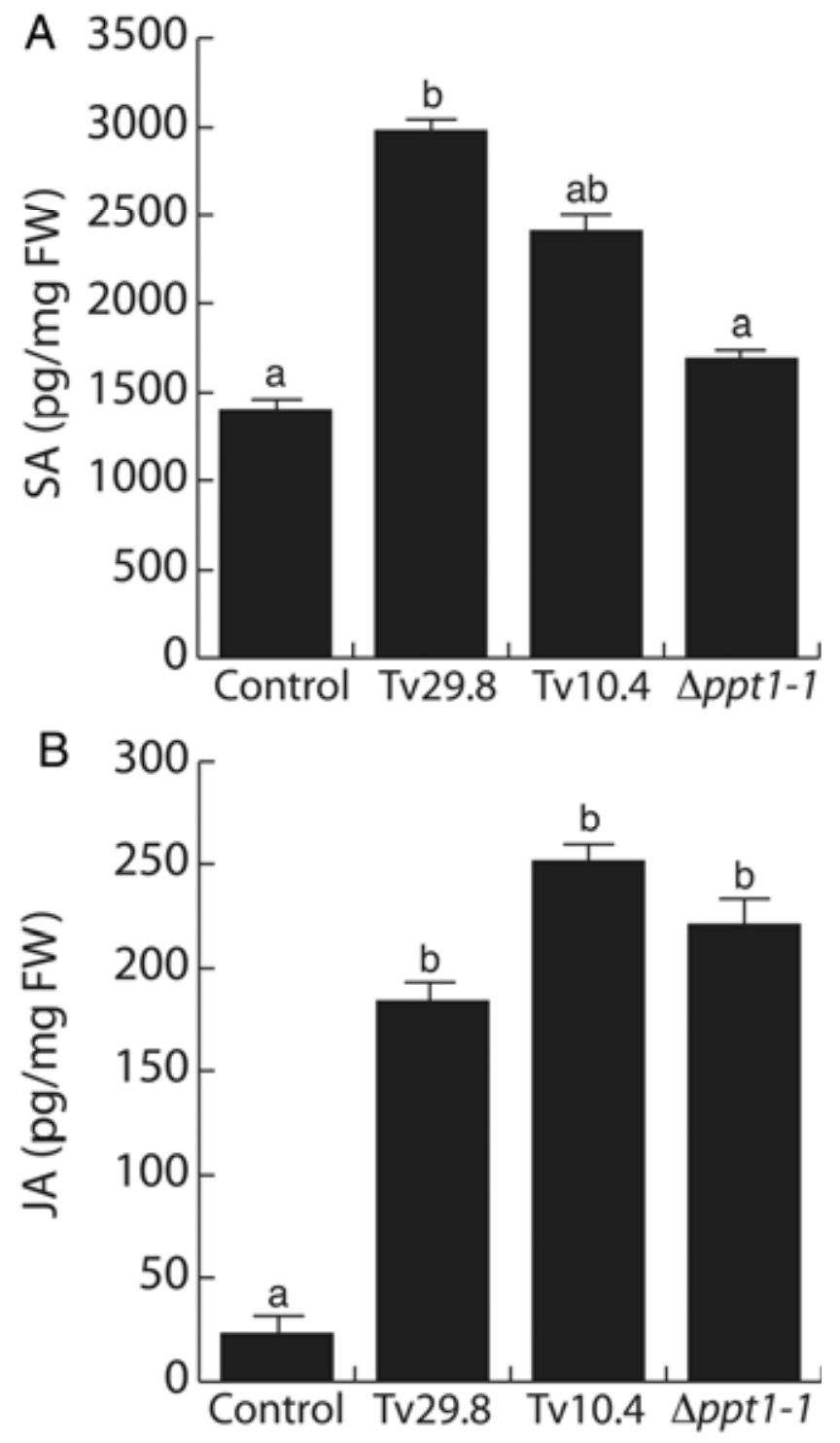

Fig. 7. Effect of Trichoderma virens on salicylic acid (SA) and jasmonic acid (JA) accumulation in Arabidopsis thaliana. Wild-type A. thaliana (Col-0) seedlings were germinated and grown for 4 days on $0.2 \times$ Murashige and Skoog plates, then co-cultivated with the indicated $T$. virens strains in $0.2 \times$ Murashige and Skoog medium supplemented with $300 \mu \mathrm{M}$ Lys for 8 additional days. Free A, SA or B, JA in A. thaliana shoots. Control corresponds to axenically grown seedlings. Error bars represent the standard error. Different letters are used to indicate means that differ significantly $(P<0.05)$. The experiment was repeated twice with similar results. root system as well as the wild-type strain. Interestingly, after a longer period of time, the mutant continues growing, invading the stem and leaves, which did not occur when the plant interacts with the wild-type strain. This may be interpreted as either a miscommunication effect or as a simple defect in the interaction due to the accelerated growth of the mutant.

Jasmonate and ET mediate the main defense responses of plants during infection by necrotrophic fungal pathogens, whereas SA-dependent responses and SAR were initially not predicted to play a role (Bent 2006). In the interaction of Trichoderma spp. with common bean (Phaseolus vulgaris), tomato ( $S$. lycopersicum), and A. thaliana, the fungus promotes accumulation of PR proteins (Salas-Marina et al. 2011; Woo et al. 2006). In agreement with these findings, we found that wild-type $T$. virens activated pPrla:uidA and induced a fourfold increase in the levels of SA. These responses were absent in plants co-cultivated with the $\Delta p p t 1-1$ mutant. Notably, the levels of JA and the expression of the JA-induced marker pLox2:uidA remained similarly induced by the wild type and the $\Delta p p t 1-1$ mutant, suggesting a specific role for PPT1 function during SAR.

Antimicrobial compounds can be produced as part of normal plant growth and in response to pathogens. Camalexin production has been found to be elicited by bacterial and fungal phytopathogens and possess antimicrobial activity (Glazebrook and
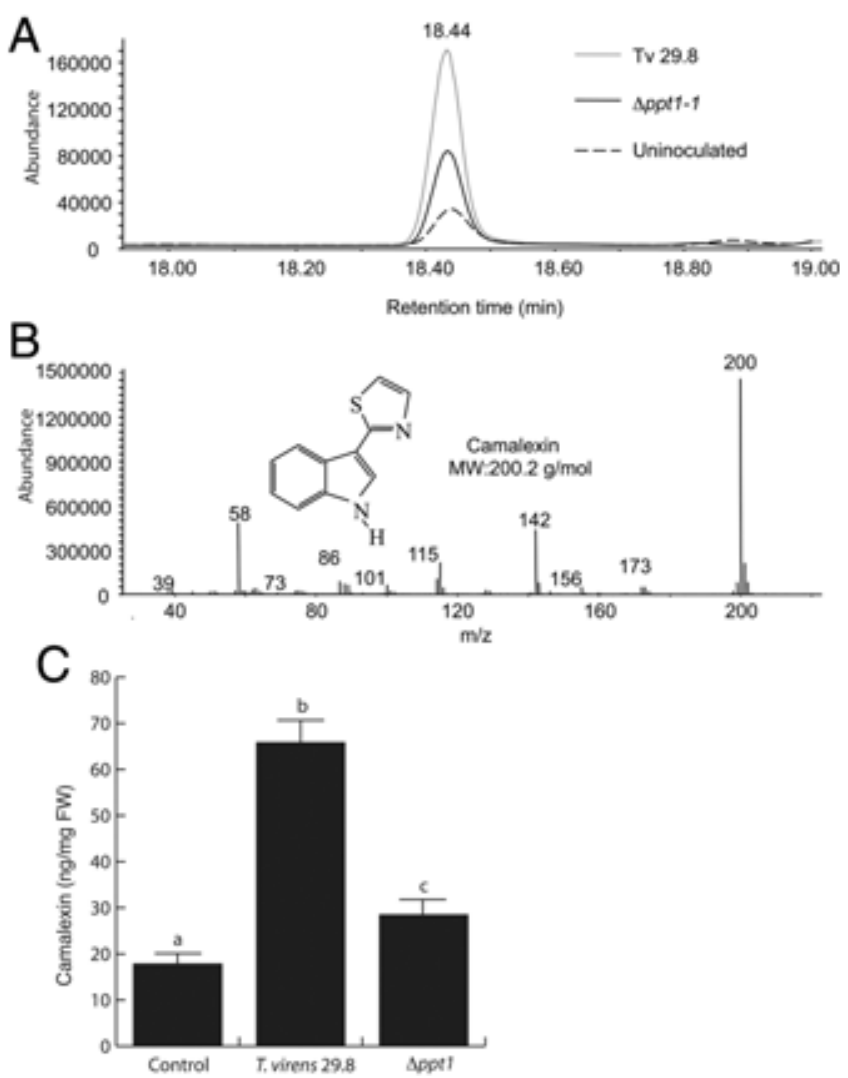

Fig. 8. Effect of Trichoderma virens inoculation on camalexin accumulation in Arabidopsis thaliana. Wild-type A. thaliana (Col-0) seedlings were germinated and grown for 4 days on $0.2 \times$ Murashige and Skoog plates, transferred to $0.2 \times$ Murashige and Skoog medium supplemented with 300 $\mu \mathrm{M}$ Lys, and then co-cultivated with the indicated T. virens strains for 8 additional days. A, Representative chromatogram showing camalexin levels in leaves of wild-type A. thaliana seedlings. Control corresponds to axenically grown-seedlings. B, Mass spectra from camalexin standard. C, Camalexin quantification from Arabidopsis leaves. The bars show the mean \pm standard deviation of three independent biological replicates. Different letters are used to indicate means that differ significantly $(P<0.05)$. The experiment was repeated twice with similar results. 
Ausubel 1994; Ferrari et al. 2003; Thomma et al. 1999). Here, we showed that $A$. thaliana seedlings colonized with wild-type T. virens accumulated higher levels of camalexin than axenically grown seedlings. This response was compromised in plants co-cultivated with the $\Delta p p t 1-1$ mutant.

In agreement with the role of PPT1 in activating defensesignaling pathways, a Trichoderma mutant lacking PPT1 failed to confer protection against the fungal necrotizing pathogen $B$. cinerea. In this regard, it has been previously shown that Arabidopsis resistance to $B$. cinerea involves SA and camalexin (Ferrari et al. 2003). Arabidopsis pad2-1 and pad3-1 mutants, which accumulate low levels of camalexin, are highly susceptible to $B$. cinerea, and purified camalexin inhibits growth of this pathogen in a dose-dependent manner (Ferrari et al. 2003; Glazebrook et al. 1997). The relation found between reduced $\mathrm{SA}$ and camalexin production and much lower protection in plants colonized by the $T$. virens $\Delta p p t 1-1$ mutant confirmed that the combined activation of SA-dependent pathways and camalexin production are important to confer plant immunity against a fungal necrotizing pathogen. Based on these analyses, we conclude that $T$. virens is capable of regulating multiple defense responses. In addition to the defense gene induction and hormone biosynthesis, we now provide chemical evidence supporting a role for pptl from $T$. virens in phytoalexin induction, another important defense response.

In conclusion, we have shown the important role of the 4phosphopantetheinyl transferase PPT1 from T. virens in secondary metabolism and plant defense responses. Among the several mechanisms activated in A. thaliana by $T$. virens to confer immunity against $B$. cinerea, there is a role of $p p t l$ in a resistance mechanism involving SA and camalexin production.

\section{MATERIALS AND METHODS}

Fungal strains and culture conditions.

The $T$. virens wild-type strain Tv29.8 and an arginine auxotroph (Tv10.4) derived from it were used in this study (Baek and Kenerly 1998). T. virens strains were grown in potato dextrose agar (PDA) medium (Difco Laboratories, Detroit) or in Vogel's minimal medium supplemented with $2 \mathrm{mM}$ arginine. Pathogenic strains of $R$. solani, F. oxysporum, Fusarium spp., Alternaria solani, Sclerotium rolfsii, S. cepivorum, and Phytophthora capsici were grown in PDA medium (Difco Laboratories). T. virens $\Delta p p t 1$ mutants were grown in Vogel's minimal medium supplemented with $10 \mathrm{mM}$ lysine or $50 \%$ siderophorecontaining conditioned medium. To prepare siderophore-containing medium, $1 \times 10^{9}$ conidia from strain Tv29.8 were used to inoculate Vogel's liquid minimal medium without iron (Marquéz-Fernández et al. 2007).

\section{Cloning and overexpression of ppt1.}

Based on the $T$. virens genome sequence, forward primer F_orf_pptl and reverse primer $R \_o r f \_p t 1$ (Table 1) were designed and used to amplify by PCR the 4-phosphopantetheinyl transferase-encoding gene (pptl) from the wild-type strain Tv29.8 using genomic DNA as template and the following conditions: an initial cycle of $95^{\circ} \mathrm{C}$ for $3 \mathrm{~min}$; 30 cycles of
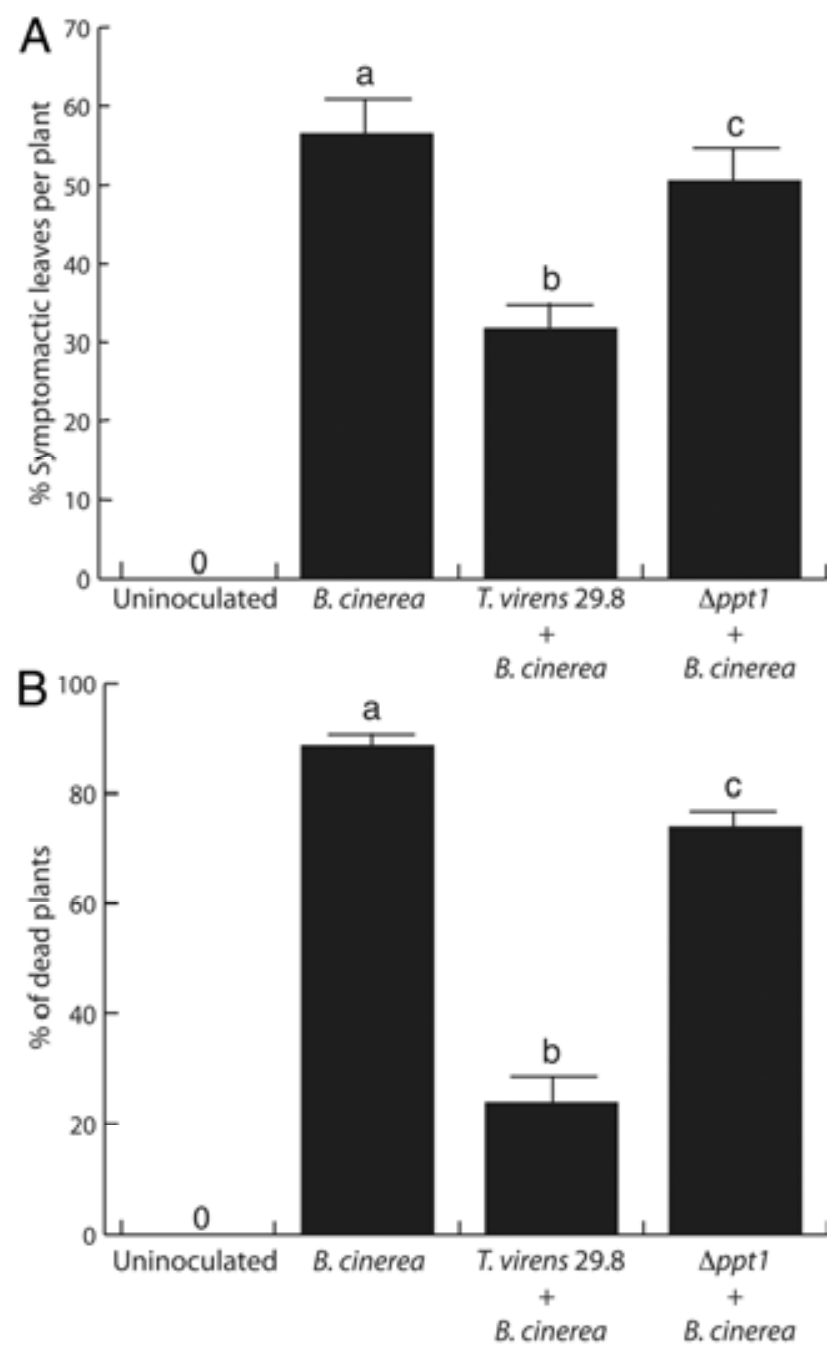

Fig. 9. Protection against Botrytis cinerea in Arabidopsis thaliana seedlings is compromised in $\Delta p p t 1$ mutants. A, A. thaliana plants (12 days old) grown axenically or co-cultivated for 6 days with the indicated Trichoderma virens strains in vitro were placed in petri dishes containing $0.2 \times$ Murashige and Skoog medium, and the shoot was treated with sterilized deionized water or inoculated with $1 \times 10^{6} \mathrm{~B}$. cinerea spores, distributing the inoculum over the leaf surface. Each treatment was applied to 30 plants. A, Number of symptomatic leaves per plant was scored 3 days postinfection and $\mathbf{B}$, the percentage of dead plants was scored 5 days postinfection. Bars show the mean \pm standard deviation of 30 A. thaliana seedlings. Different letters are used to indicate means that differ significantly $(P<0.05)$. The experiment was repeated twice with similar results.

Table 1. List of primers of Trichoderma virens

\begin{tabular}{|c|c|c|c|}
\hline Name & Sequence & Temperature $\left({ }^{\circ} \mathrm{C}\right)$ & Size $(\mathbf{b p})^{\mathrm{a}}$ \\
\hline F_orf_ppt1 & 5'-TCGCAGCCATGGCTCAGCCCA-3' & 60.8 & 987 \\
\hline R_orf_ppt1 & 5'-AATCGCCATCTCACTCGCCCAGC-3' & & \\
\hline$p p t 1 \_A$ & 5'-GAGACGCAGTAGGTTCTTTC-3' & 60.8 & 1,006 \\
\hline ppt1_B & 5'-CGCCGTGGGGCTCTGTATCGACAAGCTGGCTGCAGCGATCATTTATATGTCG-3' & . & $\ldots$ \\
\hline ppt1_C & 5'-CGCAACGAATAATCCCTCCCTGTAGAAGGCAAGATCACCGACAAGTTGGTCG-3' & 60.8 & 857 \\
\hline ppt1_D & 5'-TAAGCATGGGGCGCCACAGTTGC-3' & & \\
\hline ppt1_E & 5'-TTGATATCGAGCCCCCAGGCG-3' & 53.8 & 2,929 \\
\hline$p p t 1 \_F$ & 5'-GGAATTGGGTCTGGCACG-3' & & \\
\hline ppt1_G & 5'-CGCTTTAAACGGGCGTCTGTTC-3' & 65 & 4,792 \\
\hline$p p t 1 \_H$ & 5'-GGGGACTTTGAGCTGAAGTGGATG-3' & $\ldots$ & $\ldots$ \\
\hline
\end{tabular}

${ }^{a}$ Size of the amplified fragment using the corresponding pair of oligonucleotides. 
$94^{\circ} \mathrm{C}$ for $45 \mathrm{~s}, 60.8^{\circ} \mathrm{C}$ for $45 \mathrm{~s}$, and $72^{\circ} \mathrm{C}$ for $1 \mathrm{~min}$; and a final cycle of $72^{\circ} \mathrm{C}$ for $7 \mathrm{~min}$. The PCR product was cloned into PCR 2.1 TOPO (Invitrogen, Carlsbad, CA, U.S.A.). To generate the overexpression plasmid, one of the clones was selected and plasmid DNA was digested with EcoRI and subsequently ligated into plasmid pUE08 (Esquivel-Naranjo and HerreraEstrella 2007). DNA of the resulting plasmid (pOEppt) was used in polyethylene glycol-mediated transformation of protoplasts of the Tv29.8 strain, as described previously (Baek and Kenerly 1998). Hygromycin-resistant transformants were subjected to three consecutive monosporic passes. Southern blot analysis was used to confirm plasmid integration, using as a probe a fragment of the pptl gene containing the complete open reading frame.

Replacement of the phosphopantetheinyl transferase gene.

Gene ppt 1 was replaced in strain Tv10.4 by the $T$. virens arg2 gene using the double-joint PCR procedure described by Yu and associates (2004). In a first round of PCR, 5' forward primer ppt1_A, 5' reverse primer ppt1_B, 3' forward primer $p p t 1 \_C$, and 3 ' reverse primer ppt1_D (Table 1) were used to generate the upstream and downstream regions flanking the pptl gene. In addition, to generate the marker cassette, the following primers were used: $\arg 2$ forward primer $p p t 1_{-} E$, and arg2 reverse primer $p p t 1 \_F$ (Table 1$)$. In the third and final round of amplification, we used the nested forward primer $p p t 1 \_G$ and reverse primer ppt1_H (Table 1). The final product was used to transform protoplasts. Selection of transformants was carried out in Vogel's minimal medium. For the selection of transformants, it was considered that, initially, transformants could require lysine and siderophores, which were added to the medium for the recovery of transformed protoplasts. All arginine prototrophs were subjected to three rounds of monosporic culture. Gene replacement was confirmed by PCR using primers ppt1_G and ppt1_H (Table 1). Putative gene replacement mutants were then confirmed by Southern blot analysis, using as probe a 1-kb fragment of the $5^{\prime}$ upstream region covering up to the translation start codon of the pptl gene.

\section{Complementation of the null mutant.}

The complete pptl gene, including the $5^{\prime}$ and $3^{\prime}$ flanking regions, was amplified by PCR with oligonucleotides $5^{\prime}$ forward primer pprl_A and 3' reverse primer ppt1_D (Table 1) using genomic DNA of the wild-type strain. The PCR conditions were an initial cycle at $95^{\circ} \mathrm{C}$ for $3 \mathrm{~min} ; 30$ cycles of $45 \mathrm{~s}$ at $94^{\circ} \mathrm{C}, 3 \mathrm{~min}$ at $55.7^{\circ} \mathrm{C}$, and $1 \mathrm{~min}$ at $72^{\circ} \mathrm{C}$; followed by a final cycle at $72^{\circ} \mathrm{C}$ for $7 \mathrm{~min}$. The PCR product was cloned into TOPO PCR 2.1 (Invitrogen). The resulting plasmid, named ppt1-complement $(7 \mathrm{~kb})$, was used in co-transformation experiments using, as selectable plasmid, pCB1004 (FGSC), which carries a hygromycin resistance cassette, and protoplasts of the gene replacement mutant ( $\Delta p p t 1-1)$. Hygromycin-resistant transformants were then transferred to medium without lysine and siderophores and were subjected to three rounds of monosporic culture. These transformants were designated $T$. virens complemented (TvC). Confirmation of transformation was carried out by PCR amplification of the ppt 1 gene followed by Southern blot analysis

\section{Phenotypic analysis of mutants.}

Overexpressing strains, gene-replacement mutants, complemented strains, and Tv29.8 and Tv10.4; were grown in the dark on PDA, and radial growth of the colonies measured at 24, 48, and $72 \mathrm{~h}$. To determine the effect of the manipulation of the ppt 1 gene in the production and development of conidiophores, all strains were grown in Vogel's medium and incubated at $28^{\circ} \mathrm{C}$ for
5 days with white light illumination. For analysis of conidial germination, the medium used was Grimm-Allen (Vittone 2008) with and without ferric chloride and ferrous sulfate.

\section{Antibiosis.}

For antibiosis tests, all strains were inoculated in plates containing PDA covered by a sterile cellophane membrane and incubated for $48 \mathrm{~h}$ in total darkness. The cellophane was removed together with the mycelium, an agar disk carrying mycelium of the indicated fungus placed on the antagonist-free medium, and the plates further incubated for $48 \mathrm{~h}$ in total darkness.

\section{Determination of peptaibols.}

$T$. virens strains were inoculated in VMS medium as described by Viterbo and associates (2007), with some modifications. In this case, fermentation was allowed to proceed for 9 days with constant agitation and sucrose as carbon source to $1.5 \%$. Mycelium was harvested and lyophilized. In total, 250 $\mu \mathrm{l}$ of mixture A (methanol, water, an acetonitrile in a 1:1:1 ratio) or mixture $\mathrm{B}$ ( $5 \%$ acetonitrile and $0.1 \%$ formic acid) was added to $5 \mathrm{mg}$ of dry mycelia. The suspension was homogenized for $15 \mathrm{~min}$ in vortex, with subsequent sonication for 15 min. The mixture was then centrifuged at $12,000 \mathrm{rpm}$ for 15 min and the supernatant collected and concentrated in a vacuum evaporation system to a final volume of $50 \mu$. The extract $(10 \mu \mathrm{l})$ was taken and passed through a C18 micro-column (Zip Tip, Millipore, Bedford, MA, U.S.A.) as recommended by the supplier, and eluted with $5 \mu \mathrm{l}$ of a mixture of solvents (60\% acetonitrile and $1 \%$ formic acid), for ESI-QTOF analysis.

\section{Root colonization.}

Solanum lycopersicum var. Rio Grande (Emerald) seeds were surface disinfected and germinated on water agar $(1.5 \%)$ in a climate chamber at $25^{\circ} \mathrm{C}$ for 3 days with a photoperiod of $16 \mathrm{~h}$ of light and $8 \mathrm{~h}$ of darkness. Germinating seeds were then transferred to 150 -mm-diameter petri dishes (three per plate), containing $0.5 \%$ Murashige and Skoog medium (Murashige and Skoog basal salts mixture; Sigma-Aldrich, St. Louis) and $0.5 \%$ agar, placed at a 65-degree angle to prevent root burial into the medium. Seelings were incubated at $25^{\circ} \mathrm{C}$ until the development of two true leaves. A disk of mycelium of strains Tv29.8, Tv10.4, $\Delta p p t 1$, and TvC was placed near the root area. Media were supplemented with $10 \mathrm{mM}$ lysine or $2 \mathrm{mM}$ arginine in the case of the spptl mutant and the Tv10.4 strain, respectively. The root system overgrown by Trichoderma spp. was collected with the help of a scalpel. Samples were placed in two dyes, one that stains the nuclei of root cells (propidium iodide to $20 \mu \mathrm{g} / \mathrm{ml}$ ) and one that stains chitin in fungal cell wall (WGA Alexa Flour 488; $10 \mu \mathrm{g} / \mathrm{ml}$ ) (Invitrogen). Samples were visualized at the National Institute of Neurobiology Campus Juriquilla, Mexico, in a Nikon Eclipse E-600 PCM 2000 confocal microscope. Images were obtained with the $\times 40$ objective.

\section{Isolation of $\boldsymbol{T}$. virens from roots of $S$. lycopersicum.}

According to the methodology described above, seedlings once colonized in vitro by Trichoderma spp. were transplanted into sterile soil, and allowed to grow for an additional 15-day period. The roots were then collected, fragmented, and placed on Rose Bengal selective medium for the isolation of Trichoderma spp. (Ahmed et al. 1999). In the case of roots colonized by auxotrophic strains, lysine or arginine was added to the medium. Root fragments were incubated at $28^{\circ} \mathrm{C}$ until the appearance of colonies. Genomic DNA was extracted from each of the recovered colonies, as reported by Raeder and Broda (1985), to detect the strains, and analyzed by PCR using primers ppt1_G and ppt1_H(Table 1). 


\section{Seed protection assays.}

One-liter polypropyline pots containing sterile soil were inoculated with $R$. solani according to Brunner and associates (2005). Seeds were surface sterilized with $95 \%$ (vol/vol) ethanol for $5 \mathrm{~min}$ and $20 \%$ (vol/vol) sodium hypochlorite for $7 \mathrm{~min}$, followed by five washes in distilled water. Ten $S$. lycopersicum seeds were placed per pot, with three replicates per treatment. Four discs of mycelium of the indicated T. virens strain were added near the area where the seeds were sown. Seeds were incubated in a growth chamber at $28^{\circ} \mathrm{C}$ until the emergence of two true leaves. The results were validated with analysis of variance statistical analysis with a Tukey-Kramer multiple comparison test $(\alpha=0.05)$, using the Statistical Analysis and Graphics software package (version NCSS 2007).

\section{Arabidopsis co-cultivation experiments.}

A. thaliana Columbia-0 (Col-0) ecotype wild type, a transgenic line carrying a JA-inducible pLox2:uidA construct (Schommer et al. 2008), and a transgenic line carrying an SAinducible pPrla:uidA construct (Shah et al. 1997) were used throughout this work. Seeds were surface sterilized as described above, germinated, and grown on agar plates containing $0.2 \times$ Murashige and Skoog medium. Plates were settled vertically at an angle of $65^{\circ}$ to allow root growth along the agar surface and to allow unimpeded aerial growth of the hypocotyls. Plants were placed in a Percival AR95L growth chamber with a photoperiod of $16 \mathrm{~h}$ of light and $8 \mathrm{~h}$ of darkness, light intensity of $200 \mu \mathrm{mol} \mathrm{m} \mathrm{s}^{-1}$, and temperature of $24^{\circ} \mathrm{C}$.

\section{Arabidopsis inoculation experiments.}

The $T$. virens 29.8 and $\Delta p p t 1-1$ mutant strains were evaluated in vitro for their ability to elicit defense responses in $A$. thaliana. Fungal spore densities of $1 \times 10^{6}$ conidia were inoculated by placing a drop of a spore suspension at $4 \mathrm{~cm}$ in the opposite ends of agar plates containing 4-day-old germinated Arabidopsis seedlings (10 seedlings per plate). Plates were arranged in a completely randomized design. The seedlings were cultured for six additional days in a Percival AR95L growth chamber. The percentages of primary roots colonized by $T$. virens were determined with a ruler by measuring the primary root length and the surface covered by fungal hyphae. In the fungal co-cultivation experiments, the Murashige and Skoog $0.2 \times$ medium was supplemented with $300 \mu \mathrm{M}$ lysine to allow fungal growth.

\section{Histochemical analysis.}

For histochemical analysis of GUS activity, Arabidopsis seedlings were incubated 12 to $14 \mathrm{~h}$ at $37^{\circ} \mathrm{C}$ in a GUS reaction buffer (5-bromo-4-chloro-3-indolyl-b-D-glucuronide at 0.5 $\mathrm{mg} / \mathrm{ml}$ in $100 \mathrm{mM}$ sodium phosphate, $\mathrm{pH} 7$ ). The stained seedlings were cleared using the method of Malamy and Benfey (1997). For each marker line and for each treatment, at least 20 transgenic plants were analyzed. A representative plant was chosen and photographed using a Leica MZ6 stereomicroscope.

\section{SA and JA extraction and measurement.}

The SA and JA extraction and determination were performed in $A$. thaliana (ecotype Col-0) shoots at 8 days after co-cultivation with Trichoderma spp. in vitro. For sample preparation, plants were sectioned at the root/shoot interface. Plant tissues were frozen and ground in liquid nitrogen. Each sample (300 $\mathrm{mg}$ ) was placed in a polypropylene microtube, homogenized with $500 \mu \mathrm{l}$ of isopropanol/ $\mathrm{H}_{2} \mathrm{O} /$ concentrated $\mathrm{HCl}$ (2:1:0.002, $\mathrm{vol} / \mathrm{vol}$ ), supplemented with $200 \mathrm{ng}$ of orto-anisic acid (OA) (Sigma-Aldrich) as internal standard for SA, and shaken for 30 s. The tubes were centrifuged at $11,500 \mathrm{rpm}$ for $3 \mathrm{~min}$. The supernatants were collected and subjected to SA extraction with $200 \mu \mathrm{l}$ of dichloromethane. SA and JA were derivatized with acetyl chloride in methanol $(1 \mathrm{ml}$ per $250 \mu \mathrm{l})$, sonicated for $15 \mathrm{~min}$, and heated for $1 \mathrm{~h}$ at $75^{\circ} \mathrm{C}$. After cooling, the derivatized sample was evaporated and resuspended in $25 \mu \mathrm{l}$ of ethyl acetate for GC-MS analysis. A retention time and selected ion monitoring (SIM) were established for SA-methyl ester (ME) (2.3 $\mathrm{min}, \mathrm{m} / \mathrm{z} .152$, respectively), OA-ME (3.2 min, $\mathrm{m} / \mathrm{z}, 166)$, and JA-ME (7.5 min, $\mathrm{m} / \mathrm{z}, 224)$. JA was quantified by comparison with a standard curve obtained by using purified methyl jasmonate (Sigma-Aldrich).

\section{Camalexin determination.}

Camalexin was extracted from leaves of wild-type $A$. thaliana seedlings 8 days after $T$. virens inoculation. Camalexin levels were determined as described by Glazebrook and Ausubel (1994) and GC-MS analysis performed. For GC-MS analysis, $100 \mathrm{mg}$ per sample of shoot material was submerged in $800 \mu \mathrm{l}$ of methanol and kept at $80^{\circ} \mathrm{C}$ for $20 \mathrm{~min}$. The supernatant was transferred to a vial, evaporated under a stream of nitrogen, and redissolved in $10 \mu \mathrm{l}$ of methanol for GC-SIMMS analysis. The volume of injected sample was $2 \mu \mathrm{l}$. The molecular ions with $\mathrm{m} / \mathrm{z} 58,142$, and $200[\mathrm{M}]^{+}$were monitored to verify the presence of camalexin in the sample. Camalexin (retention time $18.44 \mathrm{~min}$ ) was quantified with a standard curve, using purified camalexin provided by J. Glazebrook (University of Minnesota) and dissolved in $100 \mu \mathrm{l}$ of methanol for chemical analysis.

\section{MS analysis.}

Identification and determination of all investigated compounds were performed using a GC-MS system. The samples were injected in an Agilent 6850 Series II gas chromatograph equipped with an Agilent MS detector model 5973 and a 5\% phenyl methyl silicone capillary column, $30 \mathrm{~m}$ by $0.2 \mathrm{~mm}$ by $0.25 \mathrm{~mm}$ (HP-5 MS). Operating conditions used helium $1 \mathrm{ml}$ $\mathrm{min}^{-1}$ as carrier gas, detector temperature of $300^{\circ} \mathrm{C}$, and injector temperature of $250^{\circ} \mathrm{C}$. The column was held for $3 \mathrm{~min}$ at $80^{\circ} \mathrm{C}$ and programmed at $6^{\circ} \mathrm{C} \mathrm{min}^{-1}$ to a final temperature of $230^{\circ} \mathrm{C}$ for $5 \mathrm{~min}$.

\section{Bioassays for Trichoderma spp.-induced resistance against $B$. cinerea.}

To test plant protection conferred by the wild-type and $\Delta$ ppt1 $T$. virens strains against $B$. cinerea, $A$. thaliana seedlings were inoculated with a fungal density of approximately $1 \times 10^{6}$ spores by placing the spores at $1 \mathrm{~cm}$ at the opposite ends of agar plates containing 12-day-old germinated seedlings (10 seedlings per plate). Trichoderma spp. were co-cultivated for 6 days with the plant to elicit defense responses by the physical contact of the mycelium with the root system. A. thaliana shoots were inoculated with a density of $B$. cinerea spores of 1 $\times 10^{6}$, distributing drops of the inoculum over leaf surfaces. Induced disease resistance in A. thaliana seedlings was evaluated 3 or 5 days after pathogen inoculation by scoring symptomatic leaves or percentage of dead plants, respectively, for a total of 30 plants. Plants were placed in a plant-growth chamber with a photoperiod of $16 \mathrm{~h}$ of light and $8 \mathrm{~h}$ of darkness, light intensity of $200 \mu \mathrm{mol} \mathrm{m} \mathrm{m}^{-1}$, and temperature of $24^{\circ} \mathrm{C}$.

\section{Data analysis.}

Experiments were statistically analyzed in the SPSS 10 program (SPSS, Chicago). Univariate and multivariate analyzes with a Tukey's post hoc test were used for testing differences in the biochemical analysis for SA, ICAld, camalexin measurements, number of lesions, and percentage of dead plants in wild-type $A$. thaliana. Different letters are used to indicate means that differ significantly $(P \leq 0.05)$. 


\section{ACKNOWLEDGMENTS}

We thank A. Chagolla for assistance with mass spectrometry, P. Martínez for his invaluable technical assistance, and J. L. R. Balderas for technical support. R. Velázquez-Robledo is indebted to CONACYT for a doctoral fellowship. This work was supported, in part, by grants from CONCYTEG (GTO-2008-C03-91748) and SAGARPA-CONACYT (2002-C01-1713).

\section{LITERATURE CITED}

Ahmed, A. S., Pérez-Sánchez, C., Egea, C., and Candela, M. E. 1999. Evaluation of Trichoderma harzianum for controlling root rot caused by Phytophthora capsici in pepper plants. Plant Pathol. 48:58-65.

Allen G., Bromley M., Kaye S. J., Keszenman-Pereyra D., Zucchi T. D., Price J., Birch M., Oliver J. D., and Turner G. 2011. Functional analysis of a mitochondrial phosphopantetheinyl transferase (PPTase) gene pptB in Aspergillus fumigates. Fungal Genet. Biol. 48:456-464.

Baek, J. M., and Kenerley, C. M. 1998. The arg2 gene of Trichoderma virens: Cloning and development of a homologous transformation system. Fungal Genet. Biol. 23:34-44.

Bailey, B. A., Bae, H., Strem, M. D., Roberts, D. P., Thomas, S. E., Crozier, J., Samuels, G. J., Choi, I., and Holmes, K. A. 2006. Fungal and plant gene expression during the colonization of cacao seedlings by endophytic isolates of four Trichoderma species. Planta 224:1449-1464.

Bent, E. 2006. Multigenic and induced systemic resistance in plants. Pages 26-24 in: Induced Systemic Resistance Mediated by Plant Growth-Promoting Rhizobacteria (PGPR) and Fungi (PGPF). Chapter 10. S. Tuzun and E. Bent, eds. Springer, New York.

Berthold, F. M., Eckard, B., Alfred, X. T., and Gunther, W. 1987. Role of siderophores in iron storage in spores of Neurospora crassa and Aspergillus ochraceus. J. Bacteriol. 169:5873-5876.

Brotman, Y., Makovitzki, A., Shai, Y., Chet, I., and Viterbo, A. 2009. Synthetic ultrashort cationic lipopeptides induced systemic plant defense responses against bacterial and fungal pathogens. Appl. Environ. Microbiol. 75:5373-5379.

Brunner, K., Zeilinger, S., Ciliento, R., Woo, S., Lorito, M., Kubicek, C., and Mach, R. 2005. Improvement of the fungal biocontrol agent Trichoderma atroviride to enhance both antagonism and induction of plant systemic disease resistance. Appl. Environ. Microbiol. 71:3959-3965.

Chacón, M., Rodríguez-Galán, O., Benítez, T., Sousa, S., Rey, M., Llobell, A., and Delgado-Jarana, J. 2007. Microscopic and transcriptome analyses of early colonization of tomato roots by Trichoderma harzianum. Int. Microbiol. 10:19-27.

Charlang, G., and Williamst, N. P. 1977. Germination-defective mutant of Neurospora crassa that responds to siderophores. J. Bacteriol. 32:10421044.

Chiche, T. A., Bintrim, S. B., Horswill, A. R., and Ensign, J. C. 2001. A phosphopantetheinyl transferase homolog is essential for Photorhabdus luminescens to support growth and reproduction of entomopathogenic nematode Heterorhabditis bacteriophora. J. Bacteriol. 183:3117-3126.

Copp, J. N., and Neilan, B. A. 2006. The phosphopantetheinyl transferase superfamily: Phylogenetic analysis and functional implications in cyanobacteria. Appl. Environ. Microbiol. 72:2298-2305.

Djonovi , S., Vargas, W. A., Kolomiets, M. V., Horndeski, M., Wiest, A., and Kenerley, C. M. 2007. A proteinaceous elicitor Sm1 from the beneficial fungus Trichoderma virens is required for induced systemic resistance in maize. Plant Physiol. 145:875-889.

Engelberth, J., Koch, T., Kühnemann, F., and Boland, W. 2000. Channel forming peptaibols are potent elicitors of plant secondary metabolism and tendril coiling. Angew. Chem. Int. Ed. Engl. 39:1860-1862.

Esquivel-Naranjo, E. U., and Herrera-Estrella, A. 2007. Enhanced responsiveness and sensitivity to blue light by blr-2 overexpression in Trichoderma atroviride. Microbiology 153:3909-3922.

Ferrari, S., Plotnikova, J. M., De Lorenzo, G., and Ausubel, F. M. 2003. Arabidopsis local resistance to Botrytis cinerea involves salicylic acid and camalexin and requires EDS4 and PAD2, but not SID2, EDS5 or PAD4. Plant J. 35:193-205.

Finking, R., Solsbacher, J., Konz, D., Schobert, M., Scäfer, A., Jahn, D., and Marahiel, M. A. 2002. Characterization of a new type of phosphopantetheinyl transferase for fatty acid and siderophore synthesis in Pseudomonas aeruginosa. J. Biol. Chem. 277:50293-50302.

Flugel, R. S., Hwangbo, Y., Lambalot, R. H., Cronan, J. E., and Walsh, C. T. 2000. Holo-(acyl carrier protein) synthase and phosphopantetheinyl transfer in Escherichia coli. J. Biol. Chem. 275:959-968.

Fravel, D. R. 1998. Role of antibiosis in the biocontrol of plant diseases. Annu. Rev. Phytopathol. 26:75-91.

García-Estrada, C., Ullán, R. V., Velasco-Conde, T., Godio, R. P., Teijeira, F., Vaca, I., Feltrer, R., Kosalková, K. A, Mauriz, E., and Martín, J. F.
2008. Post-translational enzyme modification by the phosphopantetheinyl transferase is required for lysine and penicillin biosynthesis but not for roquefortine or fatty acid formation in Penicillium chrysogenum. Biochem. J. 415:317-324.

Gehring, A. M., Mori, I., Perry, R. D., and Walsh, C. T. 1998. The nonribosomal peptide synthetase HMWP2 forms a thiazoline ring during biogenesis of yersiniabactin, an iron-chelating virulence factor of Yersinia pestis. Biochemistry 37:11637-11650.

Glazebrook, J. 2005. Contrasting mechanisms of defense against biotrophic and necrotrophic pathogens. Annu. Rev. Phytopathol. 43:295-227.

Glazebrook, J., and Ausubel, F. M. 1994. Isolation of phytoalexin-deficient mutants of Arabidopsis thaliana and characterization of their interactions with bacterial pathogens. Proc. Natl. Acad. Sci. U.S.A. 91:8955-8959.

Glazebrook, J., Zook, M., Mert, F., Kagan, I., Rogers, E. E., Crute, I. R., Holub, E. B., Hammerschmidt, R., and Ausubel, F. 1997. Phytoalexin deficient mutants of Arabidopsis reveal that PAD4 encodes a regulatory factor and that four PAD genes contribute to downy mildew resistance. Genetics 146:381-392.

Hiltunen, J. K., Chen, Z., Haapalainen, A. M., Wierenga, R. K., and Kastaniotis, A. J. 2010. Mitochondrial fatty acid synthesis an adopted set of enzymes making a pathway of major importance for the cellular metabolism. Prog. Lipid Res. 49:27-45.

Horbach, R., Graf, A., Weihmann, F., Antelo, L., Mathea, S., Liermann, J. C., Opatz, T., Thines, E., Aguirre, J., and Deising, H. D. 2009. Sfp-type $4^{\prime}$-phosphopantetheinyl transferase is indispensable for fungal pathogenicity. Plant Cell 21:3379-3396.

Howell, C. R., and Stipanovic, R. D. 1983. Gliovirin, a new antibiotic from Gliocladium virens, and its role in the biological control of $P y$ thium ultimum. Can. J. Microbiol. 29:321-324.

Howell, C. R., and Stipanovic, R. D. 1995. Mechanisms in the biocontrol Rhizoctonia solani induced cotton seedling disease by Gliocladium virens: Antibiosis. Phytopathology 85:469-472.

Jejelowo, O. A., Conn, K. L., and Tewari, J. P. 1991. Relationship between conidial concentration, germling growth and phytoalexin production by Camelina sativa leaves inoculated with Alternaria brassicae. Mycol. Res. 95:928-934.

Keating, T. A., and Walsh, C. T. 1999. Initiation, elongation, and termination strategies in polyketide and polypeptide antibiotic biosynthesis. Curr. Opin. Chem. Biol. 3:598-606.

Keszenman-Pereyra, D., Lawrence, S., Twfieg, M. E., Price, J., and Turner, G. 2003. The npgA/cfwA gene encodes a putative 4'-phosphopantetheinyl transferase, which is essential for penicillin biosynthesis in Aspergillus nidulans. Curr. Genet. 43:186-190.

Lambalot, R. H., Gehring, A. M., Flugel, R. S., Zuber, P., LaCelle, M., Marahiel, M. A., Reid, R., Khosla, C., and Walsh, C. T. 1996. A new enzyme superfamily: The phosphopantetheinyl transferases. Chem. Biol. 3:923-936.

Malamy, J. E., and Benfey, P. N. 1997. Organization and cell differentiation in lateral roots of Arabidopsis thaliana. Development 124:33-44.

Marahiel, M. A., Stachelhaus, T., and Mootz, H. D. 1997. Modular peptide synthetases involved in nonribosomal peptide synthesis. Chem. Rev. 97:2651-2674.

Márquez-Fernández, O., Trigos, A., Ramos-Balderas, J. L., ViniegraGonzález, G., Deising, H., and Aguirre, J. 2007. Phosphopantetheinyl transferase CfwA/NpgA is required for Aspergillus nidulans secondary metabolism and asexual development. Eukaryot. Cell 6:710-720.

Mootz, H., Finking, R., and Mohamed, M. 2001. 4'-Phosphopantetheine transfer in primary and secondary metabolism of Bacillus subtilis. J. Biol. Chem. 276:37289-37298.

Neuhof, T., Dieckmann, R., Druzhinina, I. S., Kubicek, C., and Döhren, H. V. 2007. Intact-cell MALDI-TOF mass spectrometry analysis of peptaibol formation by the genus Trichoderma/Hypocrea: Can molecular phylogeny of species predict peptaibol structures? Microbiology 153:34173437.

Neville, C., Murphy, A., Kavanagh, K., and Doyle, S. 2005. 4'-Phosphopantetheinyl transferase mediates non-ribosomal peptide synthetase activation in Aspergillus fumigates. Chembiochem. 6:679-685.

Oberegger, H., Eisendle, M., Schrettl, M., Graessle, S., and Haas, H. 2003. 4' Phosphopantetheinyl transferase-encoding npgA is essential for siderophore biosynthesis in Aspergillus nidulans. Curr. Genet. 44:211-215.

Ollinger, J., Song, K.-B., Antelmann, H., Hecker, M., and Helmann, J. D. 2006. Role of the Fur Regulon in Iron Transport in Bacillus subtilis. J. Bacteriol 188: 3664-3673.

Ongena, M., Jourdan, E., Akram, A., Paquot, M., Brans, A., Joris, B., Arpigny, J. L., and Thornart, P. 2007. Surfactin and fengycin lipopeptides of Bacillus subtilis as elicitors of induced systemic resistance in plants. Environ. Microbiol. 9:1084-1090.

Raeder, U., and Broda, P. 1985. Rapid preparation of DNA from filamentous fungi. Lett. Appl. Microbiol. 1:17-20. 
Reino, J. L., Guerrero, R. F., Hernández-Galán, R., and Collado, I. G. 2007. Secondary metabolites from species of the biocontrol agent Trichoderma. Phytochem. Rev. 7:89-123.

Rogers, E. E., Glazebrook, J., and Ausubel, F. M. 1996. Mode of action of the Arabidopsis thaliana phytoalexin camalexin and its role in Arabidopsis-pathogen interactions. Mol. Plant-Microbe Interact. 9:748-757.

Ryals, J. A., Urs, H. N., Williams, M. G, Molina, A., Steiner, H. Y., and Hunt, M. D. 1996. Systemic acquired resistance. Plant Cell 8:18091819.

Salas-Marina, M. A., Silva-Flores, M. A., Uresti-Rivera E. E., CastroLongoria, E., Herrera-Estrella, A., and Casas-Flores, S. 2011. Colonization of Arabidopsis roots by Trichoderma atroviride promotes growth and enhances systemic disease resistance through jasmonic acid/ethylene and salicylic acid pathways. Eur. J. Plant Pathol. 1:15-26

Schirmböck, M., Lorito, M., Yong-Li, W., Hayes, C. K., Arisan-Atac, I., Scala, F., Harman, G. E., and Kubicek, C. P. 1994. Parallel formation and synergism of hydrolytic enzymes and peptaibol antibiotics, molecular mechanisms involved in the antagonistic action of Trichoderma harzianum against phytopathogenic fungi. Appl. Environ. Microbiol. 60:4364-4370.

Schommer, C., Palatnik, J., Aggarwal, P., Chetelat, A., Cubas, P., Farmer, E., Nath, U., and Weigel, D. 2008. Control of jasmonate biosynthesis and senescence by miR319 targets. PLoS Biol. 6:1991-2001.

Schrettl, M., Bignell, E., Kragl, C., Sabiha, Y., Loss, O., Eisendle, M., Wallner, A., Arst, H. N. Jr., Haynes, K., and Haas, H. 2007. Distinct roles for intra- and extracellular siderophores during Aspergillus fumigates. PLoS Pathog. 3:1195-1207.

Segarra, G., Casanova, E., Bellido, D., Odena, M. A., Oliveira, E., and Trillas, I. 2007. Proteome, salicylic acid, and jasmonic acid changes in cucumber plants inoculated with Trichoderma asperellum strain T34. Proteomics 7:3943-3953.

Seidle, H. F., Couch, R. D., and Parry, R. J. 2006. Characterization of a non-specific phosphopantetheinyl transferase from Pseudomonas syringae pv. syringae FF5. Arch. Biochem. Biophys. 446:167-174.

Shah, J., Tsui, F., and Klessing, D. F. 1997. Characterization of a salicylic acid-insensitive mutant (sail) of Arabidopsis thaliana, identified in a selective screen utilizing the SA-inducible expression of the tms 2 gene. Mol. Plant-Microbe Interact. 10:69-78.

Simons, M., Permentier, H., de Weger, L., Wijffelman, C. A., and Ben, J. 1997. Amino acid synthesis is necessary for tomato root colonization by Pseudomonas fluorescens strain WCS365. Mol. Plant-Microbe Interact. 10:102-106.

Thomma, B. P. H. J., Nelissen, I., Eggeront, K., and Broekaert, W. F. 1999. Deficiency in phytoalexin production causes enhanced susceptibility of Arabidopsis thaliana to the fungus Alternaria brassicicola. Plant J. 19:163-171.

Tijerino A., Cardoza R. E., Moraga J., Malmierca M. G., Vicente F., Aleu J., Collado I. G., Gutiérrez S., Monte E., and Hermosa R. 2011. Overexpression of the trichodiene synthase gene tri5 increases trichodermin production and antimicrobial activity in Trichoderma brevicompactum.
Fungal Genet. Biol. 48:285-296.

Tsuji, J., Jackson, E., Gage, D. A., Hammerschmidt, R., and Sommerville, S. C. 1992. Phytoalexin accumulation in Arabidopsis thaliana during the hypersensitive reaction to Pseudomonas syringae pv. syringae. Plant Physiol. 98:1304-1309.

van Loon, L. C., Bakker, P. A. H. M., and Pieterse, C. M. J. 1998. Systemic resistance induced by rhizosphere bacteria. Annu. Rev. Phytopathol. 36:453-483.

Vinale, F., Marra, R., Scala, F., Ghisalberti, E. L., Lorito, M., and Sivasithamparam, K., 2006. Major secondary metabolites produced by two commercial Trichoderma strains active against different phytopathogens. Lett. Appl. Microbiol. 43:143-148.

Viterbo, A., Wiest, A., Brotman, Y., Chet, I., and Kenerley, C. 2007. The 18 mer peptaibols from Trichoderma virens elicit plant defence responses. Mol. Plant Pathol. 8:737-746.

Vittone, G. 2008. Genetic and functional analysis of siderophores in Trichoderma virens. Thesis, Department of Biochemistry and Biophysics, Texas A\&M University, College Station, TX, U.S.A.

Wallner, A., Blatzer, M., Schrettl, M., Sarg, B., Lindner, H., and Haas, H. 2009. Ferricrocin a siderophore involved in intra- and transcellular iron distribution in Aspergillus fumigates. Appl. Environ. Microbiol. 75:4194-4196.

Walsh, C. T., Gehring, A. M., Weinreb, P. H., Quadri, L. E., and Flugel, R. S. 1997. Post-translational modification of polyketide and nonribosomal peptide synthases. Curr. Opin. Chem. Biol. 1:309-315.

Wiest, A., Grzegorski, D., Xu, B., Goulard, C., Rebuffat, S., Ebbole, D. J., Bodo, B., and Kenerley, C. 2002. Identification of peptaibols from Trichoderma virens and cloning of a peptaibol synthetase. J. Biol. Chem. 277:20862-20868.

Woo, S. L., Scala, F., Ruocco, M., and Lorito, M. 2006. The Molecular biology of the interactions between Trichoderma spp. phytopathogenic fungi, and plants. Phytopathology 96:181-185

Yedidia, I., Benhamou, N., and Chet, I. 1999. Induction of defense response in cucumber plants (Cucumis sativus L.) by the biocontrol agent Trichoderma harzianum. Appl. Environ. Microbiol. 653:1061-1070.

Yedida, I., Shorest, M., Karem, Z., Benhamou, N., Kapulnik, Y., and Chet, I. 2003. Concomitant induction of systemic resistance to Pseudomonas syringae pv. lacrymans in cucumber by Trichoderma asperellum (T203) and accumulation of phytoalexins. Appl. Environ. Microbiol. 69:7343-7353

Yu, J. H., Hamari, Z., Han, K. H., Seo, J. A., Reyes-Domínguez, Y., and Scazzocchio, C. 2004. Double-joint PCR: A PCR-based molecular tool for gene manipulations in filamentous fungi. Fungal Genet. Biol. 4:973981.

\section{AUTHOR-RECOMMENDED INTERNET RESOURCE}

Joint Genome Institute $T$. virens genome webpage: genome.jgi-psf.org/TriviGv29_8_2/TriviGv29_8_2.home.html 